Studia UBB 醒italia, Volume 64 (LXIV) 2019, June, Issue 1

Published Online: 2020-06-30

DOI: 10.24193/subbdigitalia.2019.1.1

\title{
Historical Population Database of Transylvania. A Database Manual
}

\author{
Ioan Bolovan, Bogdan Crăciun, Diana Covaci, \\ Luminița Dumănescu, Elena-Crinela Holom, Daniela Mârza, \\ Angela-Cristina Lumezeanu \\ Babeș-Bolyai University, Cluj-Napoca
}

\begin{abstract}
The Historical Population Database of Transylvania (HPDT) is a research tool developed by the Centre for Population Studies at Babeș-Bolyai University Cluj-Napoca starting with 2014, whose goal is to host digitalized information from parish registers - the main sources for population history in Transylvania and Hungary until 1895 . The database is covering roughly the period 1850-1914: from the first modern census in the Austrian Empire to the upper limit allowed by the Romanian Law 16/1996 (i.e. a tresshold of 100 years, in the present day the limit being the year 1919). Curerntly, there are more than 400.000 individuals recorded within the database, which requires constant cleaning, standardization and linkage. The main objective of this undergoing entreprise consists in providing a research tool equally useful to the scientific milieu through its rich and complex data, and to the general public by means of its genealogical interface. The present work has the purpose to document the transcription and data entry processes related to HPDT, by detailing the rules applied in transferring the information from the primary sources into the digital framework.
\end{abstract}

Keywords: Historical Databases, Historical Population, Transylvania, Historical Demography, Data-entry protocol 


\section{Introduction and structure}

The Historical Population Database of Transylvania (HPDT) emerged as the result of the omonimous project, whose main goal was to build a population database covering the period between 1850 and 1914 (from the first modern census to the limit allowed by the Romanian law in the field of persons' data research). ${ }^{1}$ This was accomplished by following the most recent methodological principles of the field, in the attempt to provide full compatibility with the latest versions of the Intermediate Data Structure (IDS) (https://ehps-net.eu/content/ids, accessed 10.05.2020), thus allowing its connection to the similar databases already existing in Europe and North America.

In designing HPDT, four major objectives for the Romanian historical population research were targeted:

- to create a database which allows ampler and more complex analyses compared to the existing state of the art;

- to reconsider the role of historical information on population and the socialeconomic perspectives opened by gaining new knowledge in the field;

- to connect the population research from Romania with the actual strive to rebuild the European historical population of the nineteenth and twentieth centuries;

- to serve as a model for similar initiatives, either in Romania or in the Central and Eastern European area.

In regard to this latter goal, within Central and Eastern Europe, historical population databases, capable to answer a diverse range of demographic and social historical interrogations, are still in an early stage of development. ${ }^{2}$ Due to its multiethnical and multi-confessional character, Transylvania represented one of the most suitable geographic regions to serve as staring point for such a scientific endeavour, but it also raised intricate challenges. This is one of the main reasons for which we decided to publish this database manual, alongside the documentation (Crăciun et alii 2015, Lumezeanu 2018, Lumezeanu 2019, Bolovan and Dumănescu 2019) and the first analytical results (Coroian 2016, Bolovan and Dumănescu 2017, Mârza 2016, Mârza 2017, Holom et alii 2018, Botoș 2019) We hope to provide a useful tool for future similar endeavours, not only in terms of structure and practice, but also by

\footnotetext{
${ }^{1}$ Historical Population Database of Transylvania was built within the framework of a project financed by the Norwegian Mechanism (EEA RESEARCH GRANTS) developed by the Centre for Population Studies, Babeș-Bolyai University, in partnership with the Norwegian Historical Data Centre, Univerity of Tromsø. The financial support (650.000 Euro) covered the period May 2014 - April 2017, but the team at CPS continues to enlarge the database, by adding information, cleaning, standardizing and linking the data. During the project implementation phase, a large team of researchers and data-entry operators brought their contribution, by piece-meal remarks, suggested improvements to the database, and in particular to the development of this database manual, for which the authors of this printed version of the Manual are indebted to all of them.

${ }^{2}$ A self-explanatory overview here: https://ehps-net.eu/databases, accessed 06.05.2020; the earliest initiatives for building a common repository of historical population sources for Central and Eastern Europe are linked to the Mosaic project: https://censusmosaic.demog.berkeley.edu/, accessed 06.05.2020.
} 
highlighting the solutions applied in order to overcome the issues raised by the complexity of the sources.

The main sources of HPDT are parish registers, giving data on baptisms, marriages, burials. For the Hungarian part of Austria-Hungary, they were filled in and kept by Churches until 1895. The registers cover diverse denominations in Transylvania: Orthodox, Greek-Catholic, Roman-Catholic, Reformed, Lutheran, Unitarian, Jewish, etc. The database was built following a source-oriented method, i.e., by replicating the original structure and information of the source to detail. It records every piece of information from the document, which greatly enhances the level of detail and accuracy of the hosted data, yet it makes the data-entry process time consuming and took a heavy toll on the building process. Having one database table for each denomination and type of event was not feasible, because it would have implied an abundance of redundant data, thus tables were built by focusing on vital events and easch was made to accommodate all fields related to the respective type of source from every denomination-based subtype of parish register. This aspect posed a challenge for the database architect because of their structural diversity and the variety of fields which differed from one denomination to another, and also changed over the course of the nineteenth century.

Another significant challenge, both for the data-entry operators and the database architect, was raised by the information in the church registers being recorded in several languages (Romanian, Hungarian, Latin, German, etc.), by making use of varying alphabets and handwriting styles (Latin, Cyrillic, Kurrentschrift, etc.). Let aside the mandatory paleography skills required, which narrowed the selection pool for the data-entry operators, it also further complicated the cleaning, standardization and linkage operations due to the constant registration of persons under different spelling variants, or the translation of the same names in different languages.

From a technical viewpoint, HPDT is a relational database created in Mysql, an open source sql server owned by Oracle. The database is stored on a Linux server. Through an interface, built in Ruby on Rails, the user can access the various features of the database management system (visualization, edit, select, update, etc.). Multiple users have access to the database at the same time, from different devices and various places. Version 6 of the database (January 2020) includes five main tables ('Births', 'Bethrotals', 'Marriages', 'Deaths', 'Godparents') plus the additional table 'Deceased relatives'. They are based on four major life events present in the sources, namely the baptisms, betrothals, marriages and burials. The main tables have between 90 and 165 fields each, mostly unique types of data that cover all the fields from the parish registers. Smaller tables are also present, covering particular types of registers or records ('Convert', 'Confirmation', 'Name change'), key-role persons ('Priest', 'Midwife') and the 'Sources'. Auxiliary normalization tables help with decreasing redundancy: 'County', 'Country', 'Denomination', 'Dispensation', 'Gender', 'Legitimacy', 'Literacy', 'Marital Status', 'Twin', 'Ethnicity'. 


\section{General principles}

\section{a. Filling in the source description sheet}

Before beginning any transcription, the first mandatory step is for the data-entry operator to become familiar with the source, by filling in the source description sheet (Annex no. 1). This type of document must contain a brief description of the document's contents, well-defined dating (chronology) items, expressed in terms of date (day, month, year) and type of calendar used by the source creator(s), a list of the priests or Rabbies mentioned within it, and / or of the secular people carrying out religious undertakings, including the mohels in case of Jewish registers. The transcriber also makes a list of the midwives mentioned by the source, along with the time limits of the period in which they have been active, expressed in terms of datesfor (day, month, year).

The source description sheet must also contain a detailing of the table headings from the parish register, in order for the data-entry operator, but also for those verifying and cleaning, to easily identify the relation between fields of the original source and those of the database. After being filled in with all the mandatory information, the source description sheet is to be sent to the members of the HPDT team responsible for specific tables: Sources, Priests, and Midwives, which verify the information, add it to the respective tables and manually assign the necessary codes for the aforementioned three categories. Only after a data-entry operator receives clearance for all three tables the actual data-entry process can technically begin.

\section{b. Extracting the information}

The information from the sources must be accurately rendered, that is the original text from the parish register must be reproduced letter by letter, complying with the transcription rules specific to each language and including any typos or other categories of errors which pertain to the original author(s) or latter editors.

All data-input forms include three types of fields:

- Simple text fields, where the information is filled in by the operator, thoroughly reproducing the data from the source register;

Exception: within the field DATE (= birth/marriage/death etc. dates), the date of the event shall be written in the format day/month/year $(\mathrm{dd} / \mathrm{mm} / \mathrm{yyyy})$;

- Drop-down lists, with predetermined values, of which the appropriate element must be selected;

- Checkboxes, for which the appropriate value must be ticked, which sometimes opens other fields to be filled in, e.g. OBSERVATIONS/ COMMENTS.

\section{Uncertain information within the source}

Sometimes, parts of the information from a field within the source may be difficult or impossible to decode, as the source has been damaged, the ink has 
washed out, the photocopy of the source is improper, or the operator cannot recognize the written word.

\section{General rule:}

If one cannot identify one or several letters from the source, or an entire word, two question marks ('??') shall be inserted within the respective field. In case there are only two possible options, both of them shall be registered into the field, separated by the special symbol '@'. In case there are two different versions of the same name, the symbol ' $\&$ ' shall be used

\section{Clarifications, exceptions and examples:}

a. In case one or several letters from a word are unclear, question marks shall be written at the questionable point of the word, for instance 'Demia?? ??meon' (see Figure 1). If there are doubts regarding the entire word, it is recomended to copy the word followed by question marks.

The uncertain information should always be highlighted with exactly two question marks. If only one is used, it is impossible to distinguish the uncertainty symbol from the regular question marks which the priest or a later editor might have used. If more than two question marks are being used, for instance one for each letter which cannot be decoded, the symbol is no longer recognized by the computer.

Corollary: if two or more question marks appear in the original source, only one shall be copied in the respective field. If their multiple occurrence is meaningful in relation to the original information, the situation should be detailed in the field COMMENTS.

Figure 1. Use of '??' symbol for unclear information in sources

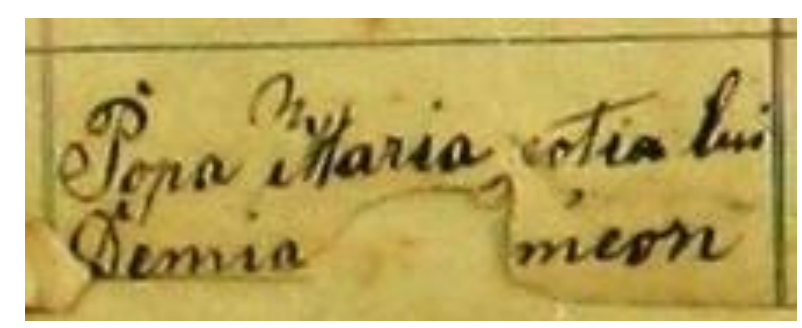

b. In case there seems to be two possible interpretations, the symbol '@' shall be used, for instance, 'Bordea@Dordea' or '1853@1858'. In case there is no difference, the first most probable option shall be used. Using this symbol involves the possibility of only two options. In the example below (see Figure 2) the data-entry operator will transcribe Kete@Zete, because the capital letter does not resemble with previous forms of the letters $\mathrm{K}$ or $\mathrm{Z}$. 
Figure 2. Use of '@' symbol when uncertain information is found in sources

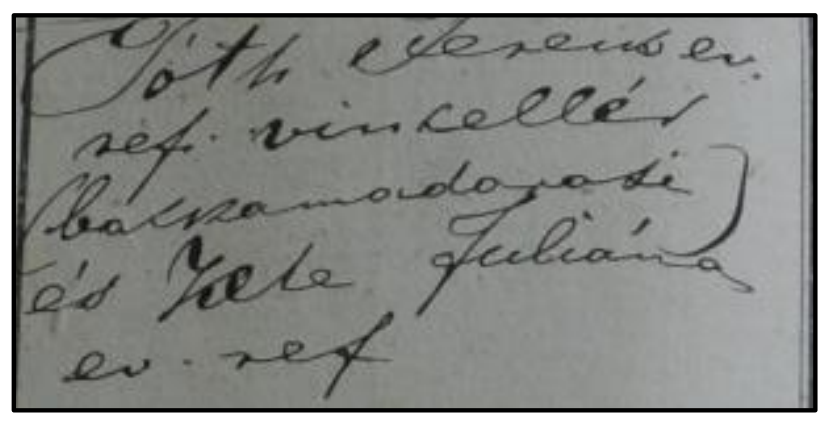

c. If two forms of the same last name/first name occur within the same registering, then they shall be written down with the symbol ' $\&$ ' between them. E.g.: 'Sofronie\&Sofron', 'Decean\&Detsan'. Unlike the symbol @, which expresses a doubt, an uncertainty, the symbol ' $\&$ ' marks the certainty of the fact that the same person appears with two or more different name forms (usually only slightly different) (See Figure 3).

Figure 3. Use of ' $\&$ ' symbol when dealing with uncertain information in source

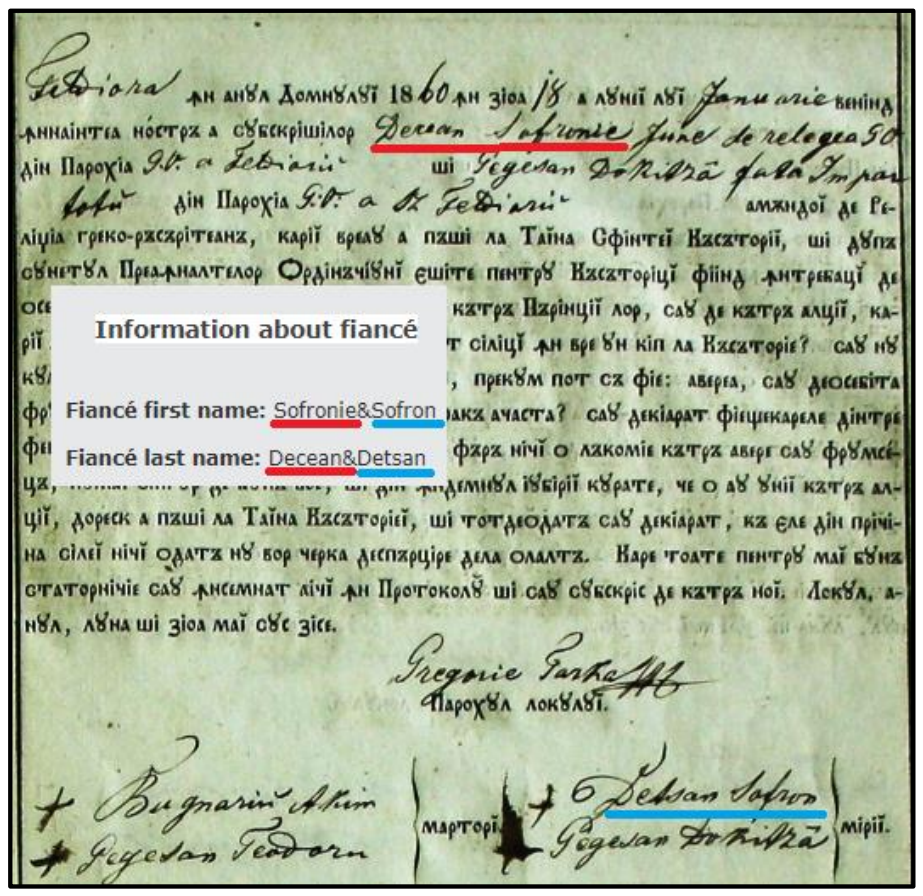

d. The possibility of using uncertainty and bracketing symbols (symbols '??' and '@') must not become a pretext for the operators so that they DO NOT do their best to interpret the information from the source!

\section{Contradictory or incorrect information within the sources}

Sometimes, the information from one field of the source can be logically incompatible with other information from the same field or from a different one. 
General rule:

Where two or several pieces of information from the source are logically incompatible, the information which is considered by the data-entry operator as being most probably erroneous shall be marked with two exclamation marks ('!!') at the end of the uncertain string. After further verification during the cleaning procedures, the information proved erroneous shall be marked in the same way.

The incorrect information should always be hightlighted by exactly two exclamation marks. If only one is being used, it is impossible to distinguish the error symbol from the exclamation marks possibly used by the priest or later editors. If you use more than two, the symbol is not longer interpreted solely by the computer.

Corollary: if two or more exclamation marks are used consecutively within the source, only one shall be copied. If their multiple occurrence is meaningful in relation with the original information, the situation should be detailed in the field COMMENTS.

\section{Data from the source is missing}

Sometimes, fields with partially or completely missing information appear in the parish registers. This is either because the priest could not get the relevant information at the time he filled in the register, or because this information has been left out purposefully, or because it was simply inadequate for a certain person, place and other data required by the register.

\section{General rule:}

If information from a field of the source is missing, although there is a heading for it in the parish register, the adequate field within the DB shall remain empty.

\section{Repetitions within the source}

The priests have often used symbols to replace recurring pieces of information in order to save effort or space (e.g. ".", "-"-", "ditto", "ibid.", "s.c.l.", "s.c.", and other similar markings). If these repetitive characters are precisely copied, all their informative value would be lost. Consequently:

\section{General rule:}

The information replaced by the repetition symbol should be copied as such within the respective field, meaning that within the DB records the last explicit entry before using the repetition symbol shall be re-copied time and again, until being replaced in the original source by new information. The repetition symbol shall not be copied in the DB. 
Clarifications, exceptions and examples:

Exception: If it is not self-evident what the repetition symbol refers to or to which piece of information it applies, the respective symbol shall be copied and the case shall be mentioned within the field COMMENTS.

\section{The additions or the interventions of the data-entry operators into the original text}

General rule:

For the sources' component of HPDT, it is recommended and preferable to avoid, to the greatest extent possible, the additions or the interventions of the operators in the texts. These interventions are accepted only when the operator considers that future users will be unable to understand the original text without such additions or interventions. For instance, the priest often used particular expression to indicate the fact that someone is living in the community such as "de aici" ("from here"/"local") instead of indicating the place. In this case it is allowed to replace "de aici" with the place indicated on the first page of the parish register.

In the exemple below (Figure 4) "de aici" was replaced by Ocna Dej in the corresponding field. Even so, the operator must consider the fact that the users shall also have access to the source picture, in order to draw their own conclusions.

Figure 4. Example of replacement: 'de aici'/'from here'

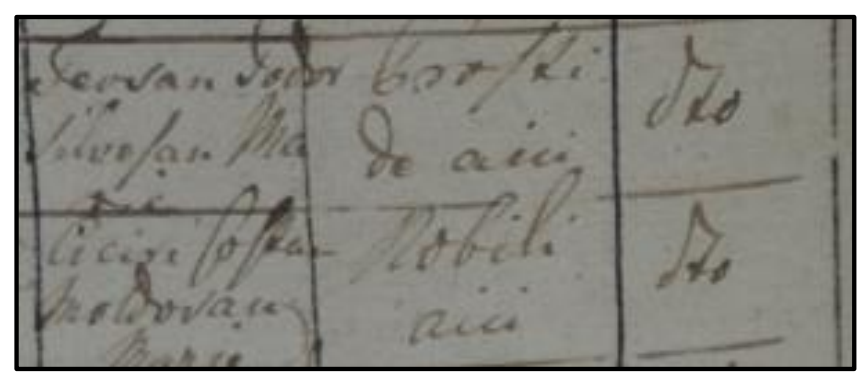

The data-entry operators' interventions upon the original text or upon translations shall be limited ONLY to the fields SOURCE OBSERVATIONS and NICKNAME and shall be placed between square brackets '[ ]'. Abbreviations shall be thus completed, irrespective of the language, exclusively in the cases when the abbreviations are very hard to understand outside the original context. If the original text has brackets: "()", "ll", "[]", " $\{$ ", they shall be copied into the DB as round brackets '()', irrespective of their original form. 


\section{Latter corrections or interventions into the original source}

All additions and completions from the parish registers shall be registered, even if they are made in the recent past, and it is obvious they are ulterior entries.

General rule:

If the parish register contains corrections/additions significant in terms of information, made after the initial entry, these shall be signaled by the symbol '\%\%' (double percentage), situated before and after the respective correction/addition.

\section{Dots and question marks within the original source}

\section{General rule:}

The dots and the question marks used within the source are to be transcribed only when significant. If the source contains several dots, or several successive question marks, these shall be copied either as '.', or as '...' (if the case), or as a single '?', irrespective of how many of them appear within the source, in order to easily distinguish them from the question marks '??' inserted by the transcription operators (see above pt. 2).

\section{Deletions from the source}

The data from a record in the original source can be altered, sometimes being crossed over, other times being replaces by a separate value added within the respective field, or can be overwritten.

\section{General rule:}

The words and sentences which are barred in the original source are to be marked with the percentage symbol '\%' before and after. Any new value (corrected) beside the deleted value shall be transcribed at the same time into the database.

Clarifications, exceptions and examples:

In case all information about a person is barred within the source, the mention 'Completely barred within the source' shall also appear in the field COMMENTS.

Exception: if the barred information appears somewhere else within the source (e.g. Figure 1), the barred information shall be ignored.

Clarification: if the deletion is applied in case of a date (e.g.: "14.07.1874"), the unbarred version shall be entered into the respective fields of the $\mathrm{DB}$, while the barred version shall be entered between '\%' in the field COMMENTS (e.g.: [Date of baptism:] ' $\% 14.07 .1874 \%$ '), as the fields dedicated to calendar dates do not allow the insertion of the symbol '\%'. If only a day or a month is barred, the field COMMENTS shall be filled in as following: $01 \% 14 \% .11 .1874$ (for the 
day) or $23.11 \% 07 \% .1874$ (for the month). In case both the day and the month are barred: $01.11 .1874 \% 14.07 . \% 1874$.

Figure 5. Error of filling in source

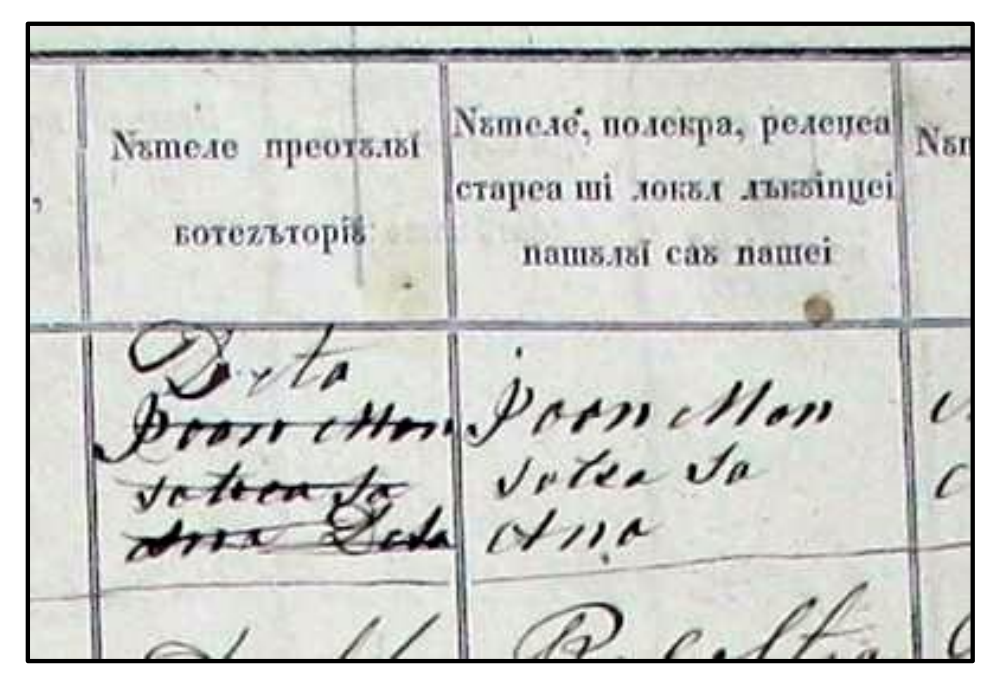

In the source, the mention "loan Man sotiea sa Ana" appears barred in a field which, according to its heading, should contain the name of the priest performing the baptism. As the same information is repeated within the following field (Information about the parents), it is obviously an error of filling in the register which the priest rectified on the spot and the barred text shall not be considered.

\section{The marking-out within the source}

In some fields, the information can be marked out (usually by underlining it) either by the priest or by somebody else.

General rule:

If, within the original source, words or complex sentences are underlined, this must not be rendered upon transcription, but it shall be mentioned mandatorily in the field COMMENTS. 


\section{Instructions specific to forms}

Upon opening the database, the welcome window (see Figure 6 below) allows the selection of one of the forms, according to the register to be copied. They are ilustrated below and they will be presented in the following sections of the manual, in the exact order of their listing into the database.

Figure 6. Main tables in HPDT

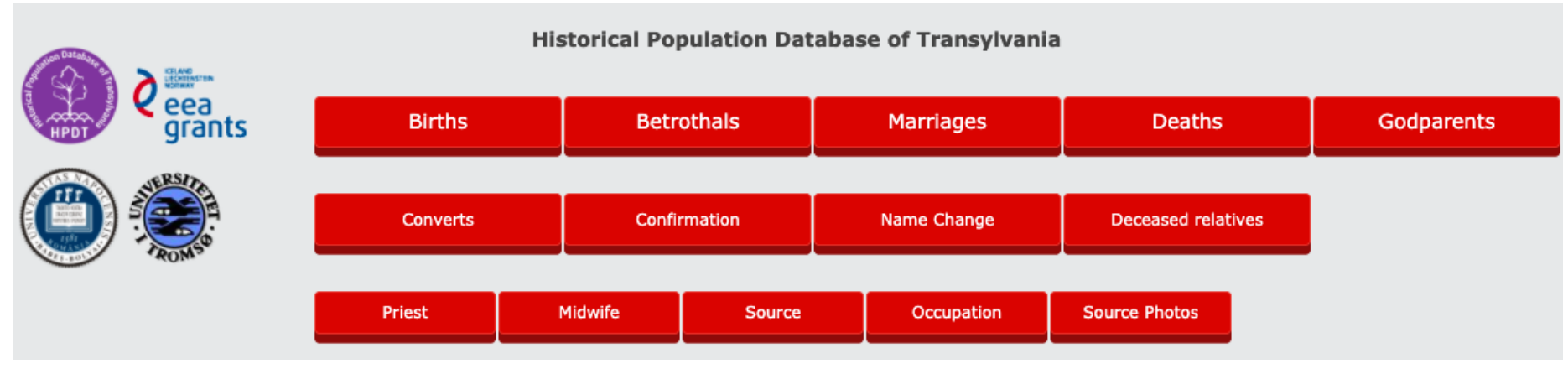

\section{Table 'BIRTHS'}

The Births (Baptisms) table has three columns, hosting data regarding the child, his parents and the baptism. The table (as well as the other tables) has many fields, but not all of them are filled in for each record. The way baptisms were recorded differed on various basis, like denomination of the register and period of recording. The information in all types of parish registers gets richer the closer one gets to the early twentieth century. In some parish registers the information is incomplete or at the minimum, barely recording the date of the baptism, the name of the child, the parents' names (in some cases only the father is nominated), the godparents, and the name of the priest who performed the baptism rite. In others, there is an abundance of information besides the above-mentioned ones (e.g. occupation of parents and godparents, address of residence, relatives, etc.). Information about the death of the baptized person can also be found, sometimes filled in decades after the original baptism record. The Births table was designed so that it could include all the information that might appear in the original records. In order to better organize the information, a separate, dedicated table has been created for godparents; this table is to be filled with all available data, along with the corresponding birth entries. This table can easily display how many children were baptized by each couple of godparents. 
Figure 7. Entry-form for table 'Births'

\begin{tabular}{|c|c|c|}
\hline Home & & \\
\hline \multicolumn{3}{|l|}{ New Birth record } \\
\hline Information about the child & Information about the parents & Information about birth \\
\hline First name & Mother first name & Midwife \\
\hline & & - \\
\hline Last name & \multirow[t]{2}{*}{ Mother last name } & \multirow{2}{*}{$\begin{array}{l}\text { Ointed } \square \text { Inoculated/Vaccinated } \square \\
\text { Inoculation/vaccination date }\end{array}$} \\
\hline & & \\
\hline Nickname & Mother nickname & Day Month Yyear \\
\hline & & Witness/Physician first name \\
\hline Gender & Mother denomination & \\
\hline Select & Select & Witness/Physician last name \\
\hline Julian calendar & Mother marital status & \\
\hline \multirow{2}{*}{ Birthday } & Select & Witness/Physician nickname \\
\hline & Mother occupation & \\
\hline $\begin{array}{l}\text { Birthday } \\
\text { Day /Month } \sqrt{\text { Year }}\end{array}$ & & Witness/Physician gender \\
\hline Baptism date & Mother birthplace & Select \\
\hline Day Month YYear & & Witness/Physician denomination \\
\hline Place of birth & Mother residence & Select \\
\hline & & Witness/Physician occupation \\
\hline Place of baptism & Mother age & \\
\hline & 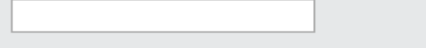 & Witness/Physician residence \\
\hline Multiple birth & Ethnicity & \\
\hline & Select & Ethnicity \\
\hline Legitimacy & Father first name & Select \\
\hline Select & & Priest \\
\hline Stillbirth & Father last name & - \\
\hline & & Date of death \\
\hline Denomination & Father nickname & Day Month $\sqrt{\text { Year }}$ \\
\hline Select & & Date of burial \\
\hline Ethnicity & Father denomination & Day /Month $\sqrt{\text { Year }}$ \\
\hline Select & Select & Place of death \\
\hline & Father marital status & \\
\hline & Select & Date of death certificate \\
\hline & Father occupation & Day $\sqrt{\text { Month }} \sqrt{\text { Year }}$ \\
\hline & & Source Observations \\
\hline & Father birthplace & $\square$ \\
\hline & & Comments \\
\hline & Father residence & $\square$ \\
\hline & & No. of recorded individuals(+ godparents) \\
\hline & Father age & \\
\hline & & Source \\
\hline & Ethnicity & - \\
\hline & Select & Source page \\
\hline Save record & & \\
\hline ck & & \\
\hline
\end{tabular}

\section{A. INFORMATION ABOUT THE CHILD}

FIRST NAME / LAST NAME / NICKNAME. The first three fields in this column account for the first name, last name and nickname of the baptized child. The information from 
the parish register should be transcribed exactly as it appears in it. If there are two or three first names, all of them will be written in the first field, following the order in which they are mentioned by the source. The abbreviated names or those with missing letters will be recorded as such, and will not be completed by the data-entry operator in this stage of data collection.

GENDER. The gender can be selected from a drop-down menu. The gender may or may not be explicitly mentioned in the baptism record. In the languages in which the registers are written (Romanian, Hungarian, German, Latin) the children's names generally allow the exact identification of their gender, even if the baptism record does not explicitly mention it. Thus, the gender corresponding to the first name, male or female, is selected from the drop-down menu. In very rare situations, when the child's gender cannot be clearly established, option 10 ('Both') should be selected (for example, the Romanian first name Sava is generally used for male children, but there have been cases of women bearing it).

JULIAN CALENDAR. This box is only ticked for Orthodox parish registers, who usually follow the Julian calendar. The usage of Gregorian or Julian calendar should be detailed in the source description sheet, following a thorough verification, including comparisons between event dates in both calendars for the respective period. If both 'old style' (Julian calendar) and 'new style' (Gregorian calendar) dates are mentioned in the original source, only the 'new style' (Gregorian) date is transcribed and the box is left unticked.

BIRTHDAY / BAPTISM DATE. It will be completed according to the format day / month / year (dd / mm / yyyy). Only the information existent in the source will be filled in; if data is missing, this field is left blank. In many registers, especially those from the beginning of the nineteenth century, only the date of baptism is mentioned. In the case of Jewish registers, the date of circumcision / receipt of the name will be entered in this field.

PLACE OF BIRTH / BAPTISM. It is only filled in with the information existing in the source; if it is missing, the field is left blank. In the latter case, under no circumstances the name of the parish to which the register pertains should be filled in to either of the two fields. In the case of the Jewish registers, the place where the circumcision / receiving the name was made will be filled in.

MULTIPLE BIRTHS. If such is the case, the checkbox 'Twins' will be ticked; this opens the field Twins, with a drop-down with three options (twins, triplets, quadruplets). The corresponding number will be selected.

LEGITIMACY. This field will be filled in only if there is an explicit mention in the register. If there is not, it will be left blank. In the case of children born out of wedlock 
and subsequently recognized by their fathers, the option 'Church illegitimate' will be selected from the drop-down menu; the mention of the subsequent recognition will be entered in the SOURCE OBSERVATIONS field. When dealing with records after 1894 there is another option to take into consideration: 'Church illegitimate/ Civil legitimate,' this situation being encountered in the cases in which the parents of the child performed only the civil marriage; thus their matrimony is legal from the State's point of view, but they are not legitimated in the eyes of the Church.

STILLBIRTH. This checkbox is ticked if it is clear that the child was born dead. Usually, in such cases, the child has no name, no godparents and no baptism priest, because he was not baptized. However, there are rare situations, where it is explicitly mentioned in the register that "he/she was born dead", but appears as baptized, with first name and surname. As a rule of thumb, in such cases, when there is no certainty that the newborn was alive or dead at birth, the box Stillbirth will be ticked anyway, and subsequent analysis will establish a model for interpreting each of these situations.

DENOMINATION. The denomination of the child will be selected from the drop-down menu only if it is explicitly mentioned by the source. Otherwise, this field will be left blank. Under no circumstances the denomination of the parish register will be filled in if there is no explicit mention in the source.

ETHNICITY. The ethnicity of the child will be selected from the drop-down menu only if it is explicitly mentioned by the source (which is the case mostly for older parish registers). Otherwise, this field will be left blank. Under no circumstances the denomination of the parish register should be taken into account as a criterion for inferring and filling in ethnicity.

\section{B. INFORMATION ABOUT THE PARENTS}

The form includes fields for the FIRST NAME / LAST NAME / NICKNAME for both parents. The transcription follows the same rules as the similar fields regarding the child. In many cases, the married women mentioned in registers (especially mothers and godmothers) are mentioned only by their maiden name. In such cases, the maiden name will be entered in the MOTHER LAST NAME field (see Figure 8 below). 
Figure 8. Mother`s maiden name

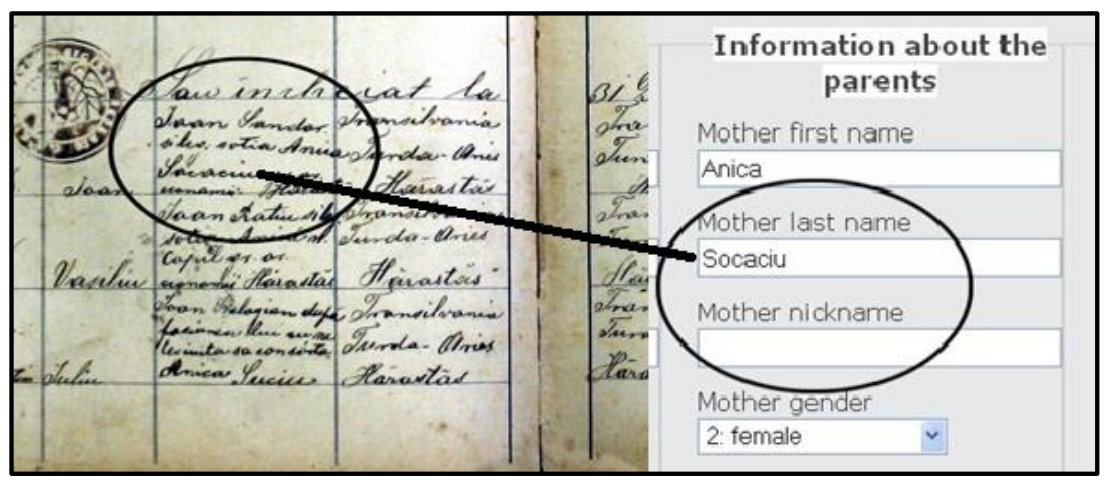

If there is information in the source about both the mother's marriage and maiden name, the latter will be trasncribed in the field NICKNAME, preceeded by the symbol '\#'. Between the various types of information in the Nickname field, the semicolon ';' symbol should be used (see Figure 9 below).

Figure 9.

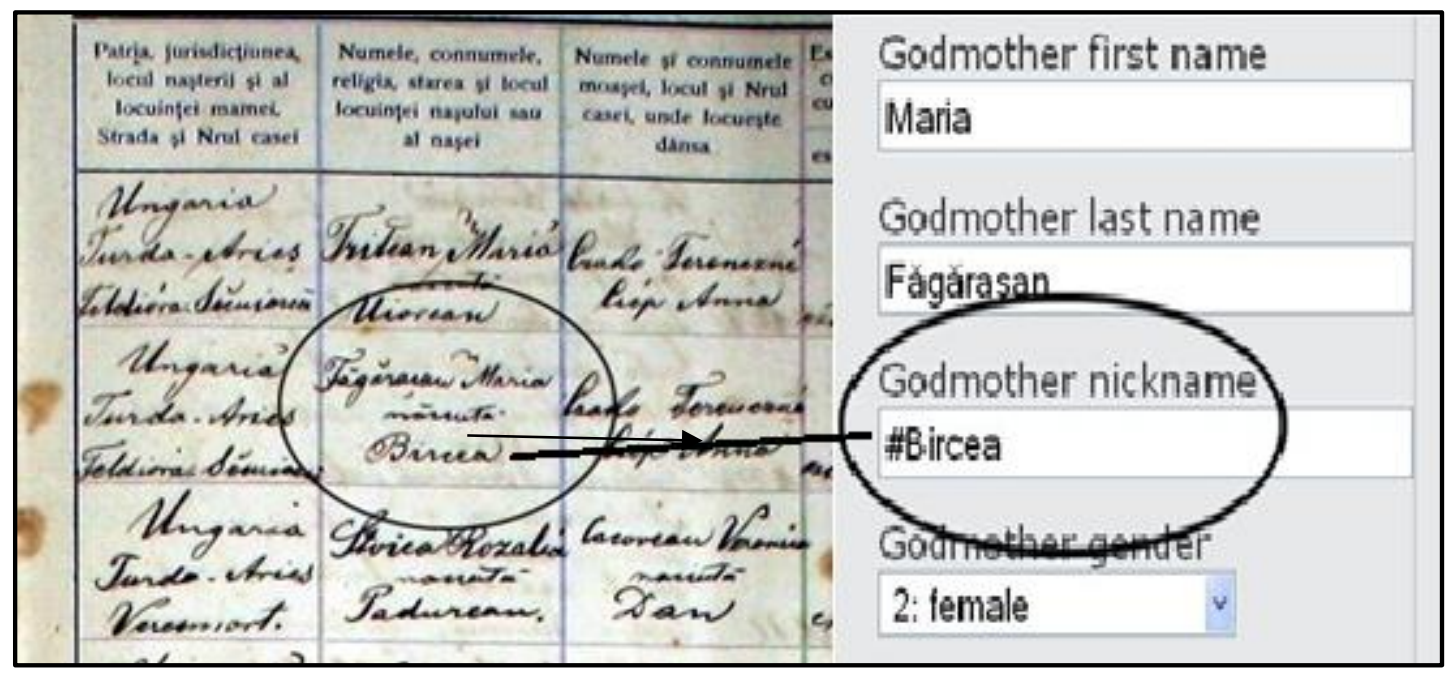

The same field can host further genealogical insights. If explicit information regarding the relationship between the subject and the persons suggested by the nickname (fathers, spouses, grandparents, etc.) appears in the source, this information will be entered in the fields that identify these persons (e.g. Figure 10 below: the source mentions "Szántó János Zsigmondé", where Zsigmond is probably the baptized child's grandfather, and the suffix 'é' highlights the relation between János and Zsigmond; this name will be filled in the field NICKNAME as 'Zsigmondé'). 
Figure 10.

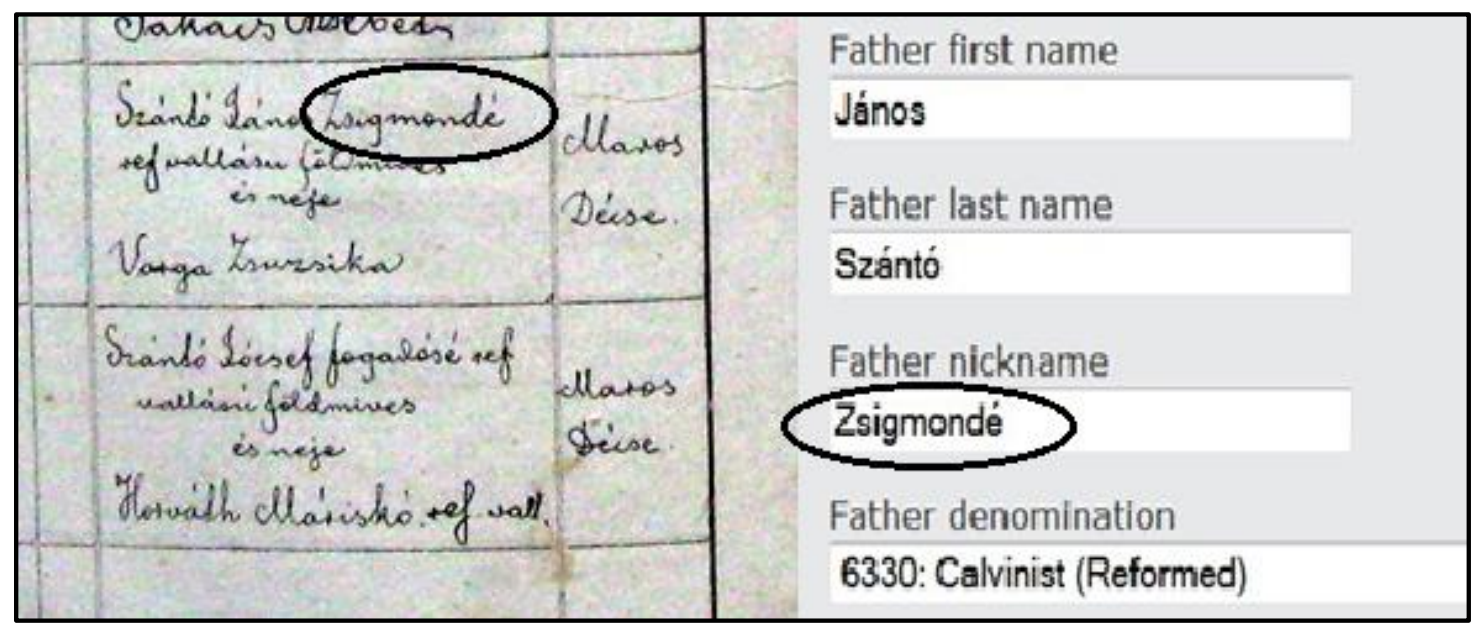

MOTHER / FATHER DENOMINATION. The same rules apply as to the similar field concerning the denomination of the child.

MOTHER / FATHER MARITAL STATUS. This can be selected from the dropdown menu only if it is explicitly mentioned in the source (married; never married / single; divorced; widowed; unmarried union; widowed living in unmarried union; civil union).

MOTHER/FATHER OCCUPATION (PRIMARY / SECOND / OTHER) fields. The entry form includes three occupation fields for each parent, given that multiple occupational titles are sometimes recorded in the parish registers for the same person. The information should be transcribed accordingly, respecting the order array from the source in case of multiple occupations. E.g., if a person is mentioned by the source having the occupations 'nobil' (nobility) and 'proprietariu' (owner), the first one will be transcribed in the field Father primary occupation and the following one in the field Father second occupation (See Figure 11 below).

Figure 11. Occupations

Father primary occupation

nobil

Father second occupation

proprietariu

Father other occupations 
The following types of information will be mandatorily recorded in the fields dedicated to occupation:

- information regarding the nobility titles (e.g. 'Nobilius', 'Comes', 'Comitissa');

- titles referring to social authority or respect (e.g. 'Illustrissima', 'Gratiosa domina', 'Spectabiles', 'Úr');

- titles within the tertiary educational field, referring to students (e.g. 'Studente', 'Student la teologie') or graduates ('Dr.');

- other information provided by the source on people's low or marginal condition (e.g. 'Saracu', 'Miser', 'Cersetor');

- a certain chronological relation between the individuals and the labor market (e.g. 'Pensionatu', 'Provisionat');

- information about the medical condition of individuals (e.g. 'Invalid', 'Orb', 'Surdu').

If the occupations are abbreviated, the exact text from the source, without any additions, shall be filled in the field designated (e.g. 'Econ.', 'Salic.', 'Spect. D.', 'Arm.').

Some of the sources provide additional information about the estate of the individuals, in form of land ownership or house propriety. In this case, the occupation will be included in the field designed for primary occupation, while the info about the house ownership will be placed in the field dedicated to the secondary occupation (see Figure 12 below). The above rules are meant to facilitate the coding of the occupational titles, status, relation and product information following the HISCO system. (van Leeuwen et alii 2002).

Figure 12. Occupation and ownership

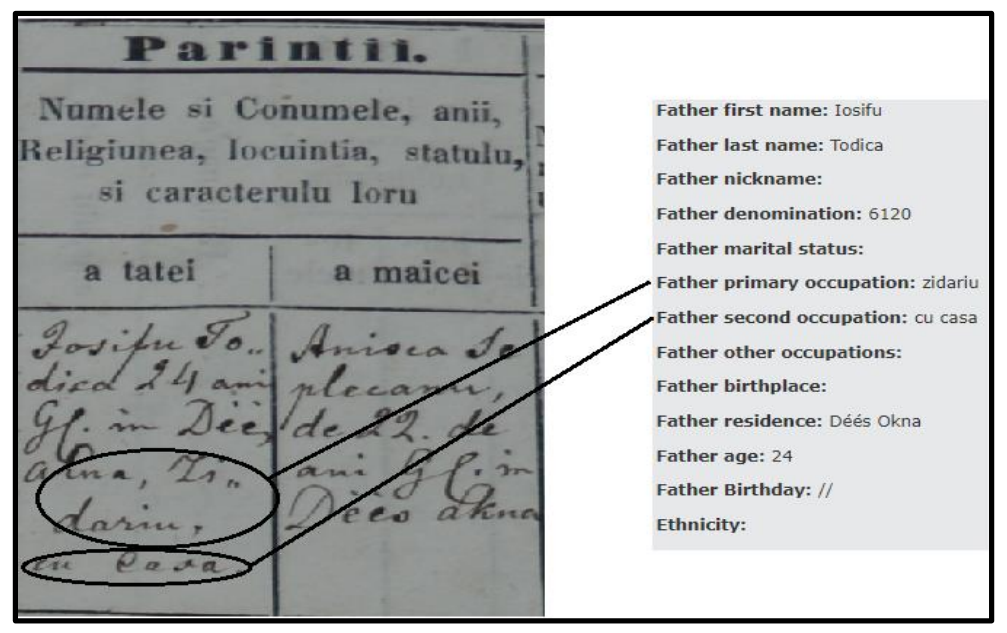

MOTHER / FATHER BIRTHPLACE. These fields are to be filled in only with information existing in the source. Same rules apply as those concerning the field Residence. 
MOTHER / FATHER RESIDENCE. These fields are to be filled in only with information existing in the source. If there is only one mention for both parents / godparents, the same information is filled out in both fields (see Figure $\mathbf{1 3}$ below: for both godparents, loan Moldovan and his wife Anna, the field Residence will be filled in with 'Hărastăs').

Figure 13. Residence

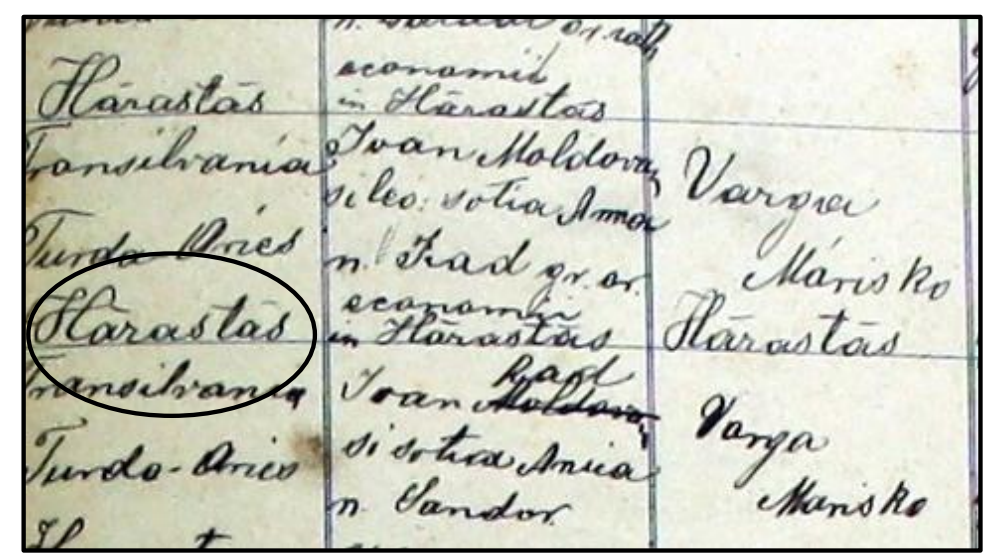

If the source also indicates the address where the parents live, it will be filled out according to the formula: town, street, number, using the exact formulations from the source (e.g.: 'Harasztos, 110' (when no street is indicated), or 'Harasztos, main street, 110' (if the street is mentioned).

As a rule of thumb, the region, the county or the district are not to be recorded, unless they are absolutely essential in identifying the locality (e.g. for localities outside Transylvania, the country or region - Hungary, Austria, etc. - should mandatorily be included, if mentioned by the source). For the localities of Transylvania, the country, county and district will be mentioned only if the locality is in a county other than the one of which the parish is a part of, and the county is explicitly mentioned by the source (see Figure 14).

Clarifications and examples:

For example, for a parish register from Viișoara, if the parents' residence is recorded in the original source as 'Ungaria, Turda, Gyeres', only 'Gyeres' (a neighbouring borough) will be recorded, because both localities, Viișoara and Câmpia Turzii (Gyeres) were part of Turda county; if it were to be 'Ungaria, Sibiu, Szerdahely comm.', then the whole string of places will be recorded. 
Figure 14. Residence recorded in source

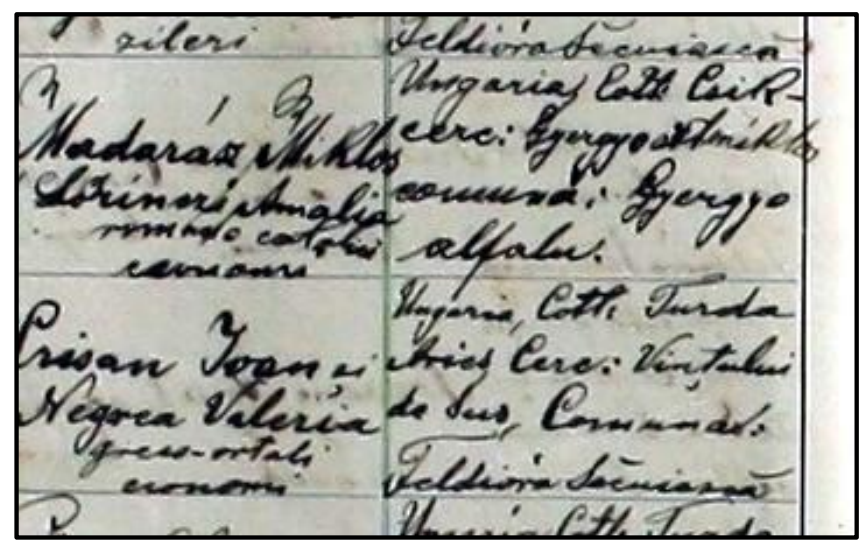

In the example from Figure 14 above, because the father ('Madarász Miklos') is from another administrative unit ('Ciuc') than that of the parish register ('TurdaArieş'), all this information will be included in the database: 'Ungaria, Csik, Gyergyoszentmiklos, Gyergyoalfalu'.

The words related to street ('strada', 'utca', etc.) will be always abbreviated by the formulas 'ut' for Hungarian ('utca') and 'st' for Romanian ('street') and German ('Strasse').

The house numbers will be inserted as they are (i.e. by using digits), avoiding the use of abbreviations such as: 'no.', 'n.', 'h.sz.', 'sz'. In the case of parish branches ('filia'), the toponym followed by 'fl' will be recorded. The abbreviations 'ut', 'st', 'fl' are never to be followed by a dot.

MOTHER / FATHER AGE. To be filled in according to the source information. If the full age is mentioned, it will be transcribed by the formula 'ymwdmh' - the age in years, months, weeks, days, hours (e.g. 28y3m5w12d6h).

MOTHER / FATHER BIRTHDAY. The same rules apply as to the similar field concerning te child's birthday.

MOTHER / FATHER ETHNICITY. The same rules apply as to the similar field concerning the ethnicity of the child.

\section{INFORMATION ABOUT BIRTH}

MIDWIFE. The midwife will be selected from the drop-down list.

OINTED / INOCULATED / VACCINATED. The corresponding box will be ticked only if the source provides information about the respective events. 
INNOCULATION / VACCINATION DATE. The date of the child's inoculation / vaccination will be recorded. If the information on innoculation / vaccination only appears sporadically, the date will be filled in for all the children recorded up until the last child register before the line in the register where the mention is made.

WITNESS/PHYSICIAN FIRST NAME, LAST NAME, NICKNAME. If the name of the person performing the vaccination / the physician's name is recorded, but there is no witness mentioned, the data about the respective person / doctor will be filled in, and in the COMMENTS field a mention should be made that the doctor is also the witness to the vaccination.

WITNESS/PHYSICIAN GENDER. The same rules apply as to the similar fields concerning the child.

WITNESS/PHYSICIAN OCCUPATION. The same rules apply as to the similar fields concerning the parents.

WITNESS/PHYSICIAN RESIDENCE. The same rules apply as to the similar fields concerning the parents.

WITNESS/PHYSICIAN DENOMINATION. The same rules apply as to the similar fields concerning the parents.

WITNESS/PHYSICIAN ETHNICITY. The same rules apply as the similar fields concerning the parents.

PRIEST. The corresponding name will be selected from the drop-down list.

DATE OF DEATH, DATE OF BURIAL, PLACE OF DEATH, DATE OF DEATH CERTIFICATE. Sometimes the baptism registers also hold details regarding the death of the baptized. If such is the case, this information will be entered in the corresponding field.

Figure 15. Source Observations and Comments in HPDT

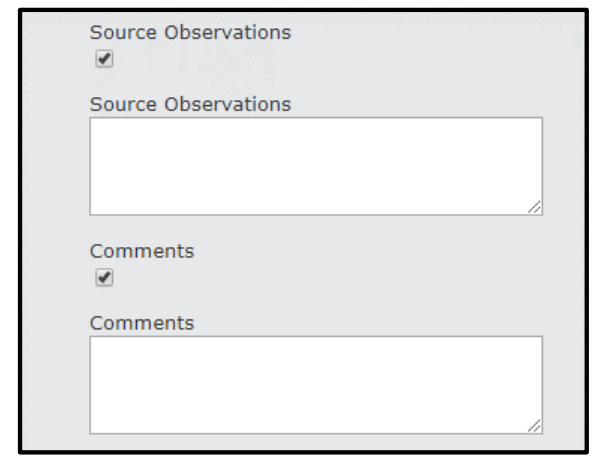


SOURCE OBSERVATIONS. If there are various remarks in the source, this box will be ticked (Figure 15 above), and the respective remarks will be transcribed in this field (e.g. the remark 'Baptized out of necesity' will be recorded in this field - see Figure 16 below)

Figure 16. Source observations

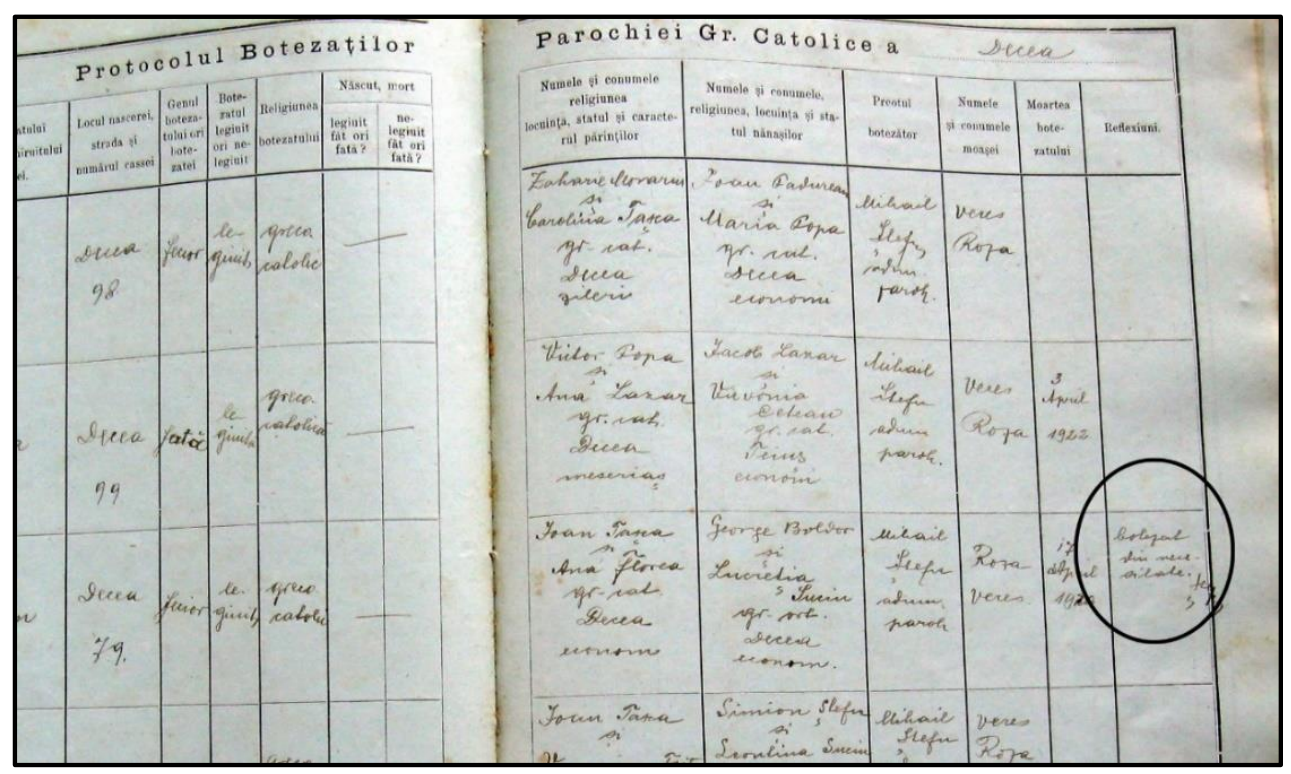

COMMENTS. If the data-entry operator has remarks, this box will be ticked and the respective comments will be recorded in the freshly opened field (see Figure 15 above).

NO. OF RECORDED INDIVIDUALS (+ GODPARENTS). This is a normalization field, related to data management purposes. In it, the data-entry operator will record the total number of individuals mentioned in a record (the child, the parents, the godparents, etc.), except for the priest and the midwife.

SOURCE. The code of the source will be selected from the drop-down list.

SOURCE PAGE. This field records the page(s) number(s) from the parish register corresponding to the record transcribed in the database. The referenced page number is the one given by the Archival service. For the information taken from the pages below, in the Source Page field will be inserted 22v-23r, because the data comes from the verso of the page 22 and the recto of the page 23 (see Figure 17 below). 
30 I.Bolovan, B.Crăciun, D.Covaci, L.Dumănescu, E.C.Holom, D.Mârza, A.C.Lumezeanu

Figure 17. Source page

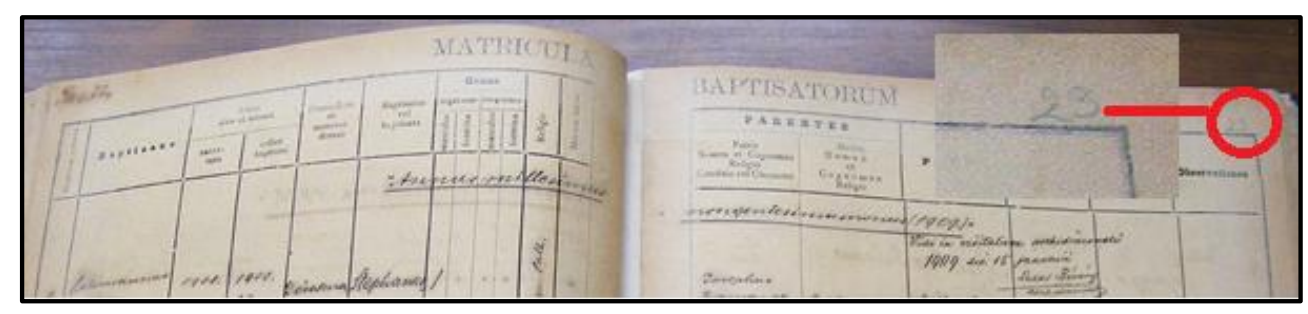




\section{Table 'BETROTHALS'}

Figure 18. Entry-form for table 'Betrothals'

\begin{tabular}{|c|c|c|c|c|}
\hline Information about fiancé & Information about fiancée & Information about betrothal & Information about parents & Other information \\
\hline Fiancé first name & Fiancée first name & $\begin{array}{l}\text { Betrothal date } \\
\text { Day } / \text { /Montr } / \text { Year }\end{array}$ & No. parents/curators & Source Observations \\
\hline Fiancé last name & Fiancée last name & Betrothal place & $\begin{array}{l}\text { Fiancé father } \square \text { Fiancé mother } \\
\text { Fiancé male curator } \square \text { Fiancé female }\end{array}$ & Comments \\
\hline Fiancé nickname & Fiancée nickname & $\begin{array}{l}\text { Wedding date } \\
\text { Day //Montr /Yyear }\end{array}$ & $\begin{array}{l}\text { curator } \square \\
\text { Reasons for fiancé parents/curators }\end{array}$ & No. of recorded individuals \\
\hline Julian calendar & $\begin{array}{l}\text { Fiancée birthday } \\
\text { Day //Montt /Yyear }\end{array}$ & Priest & Detre & Source \\
\hline $\begin{array}{l}\text { Fiancé birthday } \\
\text { Day /Montt } / \text { Year }\end{array}$ & $\begin{array}{l}\text { Fiancée denomination } \\
\text { Select }\end{array}$ & No. of witnesses & $\begin{array}{l}\text { Fancée father } \square \text { Fiancée mother } \\
\text { Fiancée male curator } \square \text { Fiancée } \\
\text { female curator }\end{array}$ & Source page \\
\hline $\begin{array}{l}\text { Fiancé denomination } \\
\text { Select }\end{array}$ & $\begin{array}{l}\text { Fiancée ethnicity } \\
\text { Select }\end{array}$ & Witness 1 first name & $\begin{array}{l}\text { Reasons for fiancée parents/curators } \\
\text { absence }\end{array}$ & \\
\hline $\begin{array}{l}\text { Fiancé ethnicity } \\
\text { Select }\end{array}$ & Fiancée residence & Witness 1 last name & Fiancé father/curator first name & \\
\hline Fiancé residence & $\begin{array}{l}\text { Fiancée marital status } \\
\text { Select }\end{array}$ & Witness 1 nickname & Fiancé father/curator last name & \\
\hline $\begin{array}{l}\text { Fiancé marital status } \\
\text { Select }\end{array}$ & $\begin{array}{l}\text { Fiancée literacy } \\
\text { Select }\end{array}$ & $\begin{array}{l}\text { Witness } 1 \text { gender } \\
\text { Select }\end{array}$ & Fiancé father/curator nickname & \\
\hline $\begin{array}{l}\text { Fiancé literacy } \\
\text { Select }\end{array}$ & & $\begin{array}{l}\text { Witness } 1 \text { literacy } \\
\text { Select } \\
\text { witness } 1 \text { ethnicity } \\
\text { Select } \\
\text { Witness } 2 \text { first name } \\
\text { Witness } 2 \text { last name } \\
\text { Witness } 2 \text { nickname } \\
\text { Witness } 2 \text { gender } \\
\text { Select } \\
\text { Witness } 2 \text { literacy } \\
\text { Select } \\
\text { Witness } 2 \text { ethnicity } \\
\text { Select } \\
\text { Witness } 3 \text { first name } \\
\text { Witness } 3 \text { last name } \\
\text { Witness } 3 \text { nickname } \\
\text { Witness } 3 \text { gender } \\
\text { Select } \\
\text { Witness } 3 \text { literacy } \\
\text { Select } \\
\text { Witness } 3 \text { ethnicity } \\
\text { Select }\end{array}$ & $\begin{array}{l}\text { Fiancé father/curator literacy } \\
\text { Select } \\
\text { Fiancé father/curator ethnicity } \\
\text { Select } \\
\text { Fiancé mother/curator first name } \\
\text { Fiancé mother/curator last name } \\
\text { Fiancé mother/curator nickname } \\
\text { Fiancé mother/curator literacy } \\
\text { Select } \\
\text { Fiancé mother/curator ethnicity } \\
\text { Select } \\
\text { Fiancée father/curator first name } \\
\text { Fiancée father/curator last name } \\
\text { Fiancée father/curator nickname } \\
\text { Fiancée father/curator literacy } \\
\text { Select } \\
\text { Fiancée father/curator ethnicity } \\
\text { Select } \\
\text { Fiancée mother/curator first name } \\
\text { Fiancée mother/curator last name } \\
\text { Fiancée mother/curator nickname } \\
\text { Fiancée mother/curator literacy } \\
\text { Select } \\
\text { Fiancée mother/curator ethnicity } \\
\text { Select }\end{array}$ & \\
\hline
\end{tabular}

The Betrothal form is meant to to facilitate the recording of data regarding the bethrotals and engagements into the database, given that some denominations (e.g. Orthodox) used dedicated parish registers for this vital event; of course, this implies unavoidable overlapping with some information from the table Marriages (see below). The table is divided into five columns, corresponding to the data regarding the fiancé and fiancée, the event itself, the parents of the prospective spouses and other general source related information. 


\section{A. INFORMATION ON THE FIANCE/FIANCEE}

FIANCÉ/FIANCÉE FIRST NAME, LAST NAME, NICKNAME. Follows the same general rules as the analogous fields from other forms, implying the unaltered transcription of the information in the original source.

JULIAN CALENDAR. The box shall be ticked in the case of the Orthodox registers, if the source description sheet requires it, or if the compilers mentioned explicitely the use of the Old Style Calendar for recording the event date.

FIANCÉ/FIANCÉE BIRTHDAY. To be filled in following the format day/month/year (dd/mm/yyyy), and only with information mentioned by the source. If part of the date is missing in the parish register, the respective fields shall not be filled in.

FIANCÉ/FIANCÉE DENOMINATION. If the source explicitely mentiones the denomination of the fiancé/fiancée, the appropriate value shall be selected from the drop-down menu. Under no circumstances the denomination of the fiancé/fiancée should be implicitely associated with the one of the parish register.

FIANCÉ/FIANCÉE ETHNICITY. If the source explicitely mentiones the ethnicity of the fiancé/fiancée, the appropriate value shall be selected from the drop-down menu. Under no circumstances the denomination of the parish register should be taken into account as a criterion for inferring and filling in ethnicity.

FIANCÉ/FIANCÉE RESIDENCE. To be filled in exactly as registered in the source, with abbreviations, accents and accented characters following the same rules detailed for the MOTHER / FATHER RESIDENCE field in table Births (see above).

FIANCÉ/FIANCÉE MARITAL STATUS. If the source mentiones the marital status of the fiancé/fiancée, the appropriate value from the drop-down list should be selected.

FIANCÉ/FIANCÉE LITERACY. To be filled in according to the contents of the source. If the signature of the fiancé/fiancée is present, option 'can write name' should be selected (Figure 19a). If the letter ' $X$ ', or a cross appears in the original source instead of the fiancé/fiancée's signature(s), the option 'cannot write name' should be selected (Figure 19b). If there is no signature, nor other sign of written aknowledgement of the document's contents, no selection should be made. 
Figure 19a. Fiancée literacy

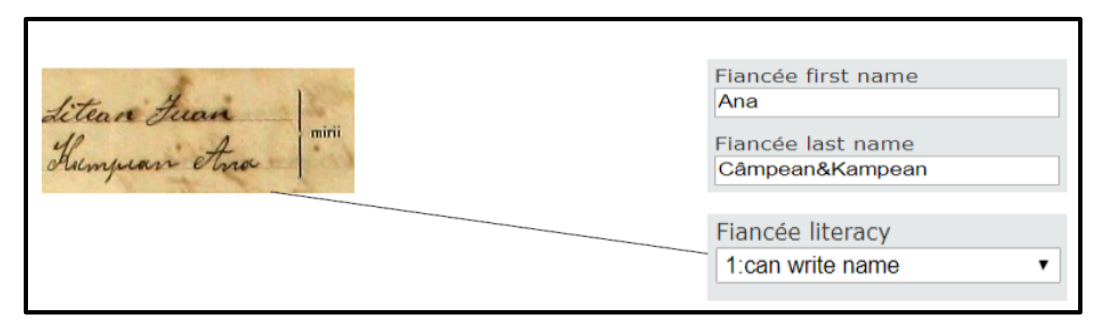

Figure 19b. Fiancée illiteracy

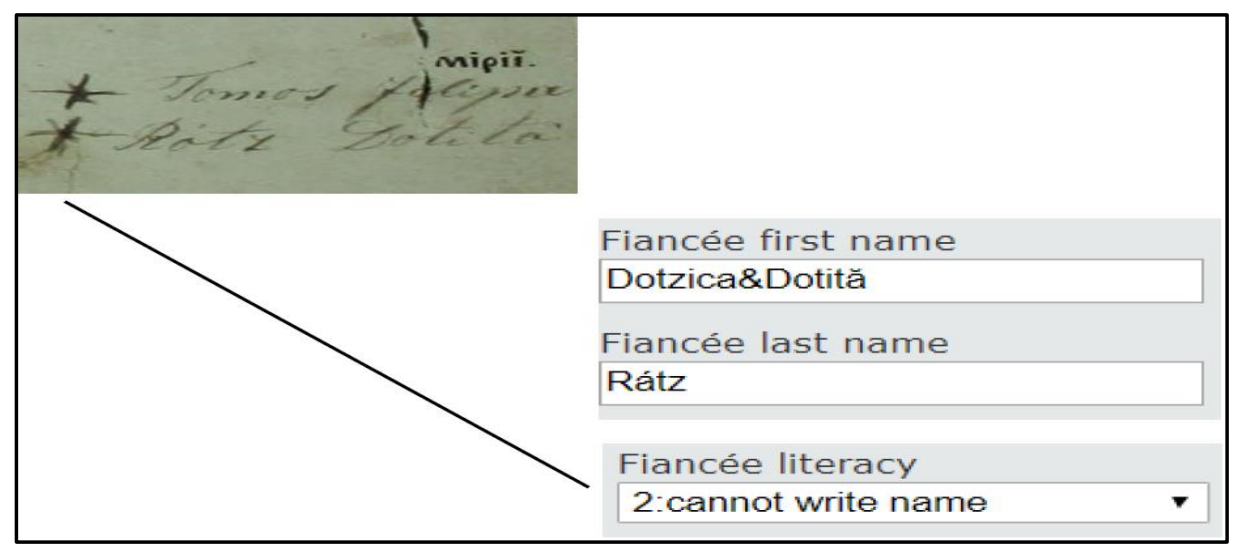

\section{B. INFORMATION ABOUT BETROTHAL}

BETROTHAL DATE. To be filled in following the format day/month/year (dd/mm/yyyy), and only with information mentioned by the source. If part of the date is missing in the parish register, the respective fields shall not be filled in.

BETROTHAL PLACE. The same rules apply as to the field FIANCÉ/FIANCÉE RESIDENCE. Under no circumstances should the name of the parish be recorded in this field if not exlicitely mentioned by the source.

WEDDING DATE. To be filled in following the format day/month/year (dd/mm/yyyy), and only with information mentioned by the source. If part of the date is missing in the parish register, the respective fields shall not be filled in.

PRIEST. The corresponding name will be selected from the drop-down list. The selection follows the same rules as for the table Births (see above).

NO. OF WITNESSES. This is a normalization field, in which the data-entry operator should fill in the number of engagement witnesses recorded in the source.

WITNESSES 1, 2 AND 3 FIRST NAME, LAST NAME, NICKNAME. Follow the same rules as the analogous fields detailed above. If there are more than three witnesses, the additional ones should be recorded within the field SOURCE OBSERVATIONS. 
WITNESSES 1, 2 AND 3 GENDER. The same rules apply as to the similar fields in the table 'Births'.

WITNESSES 1, 2 AND 3 LITERACY. The same rules apply as to the field FIANCÉ/FIANCÉE LITERACY (see above).

WITNESSES 1, 2 AND 3 ETHNICITY. The same rules apply as to the field FIANCÉ/FIANCÉE ETHNICITY (see above).

\section{INFORMATION ON THE FIANCÉ'S/FIANCÉÉ'S PARENTS}

NO. PARENTS/CURATORS. This is a normalization field, in which the data-entry operator should fill in the number of parents/curators recorded as having attended the betrothal.

FIANCÉ/FIANCÉE: MOTHER/FATHER/MALE CURATOR/FEMALE CURATOR. The adequate box (-es) should be ticked for indicating the respective individuals recorded as having attended the betrothal (see Figure 20 below).

Figure 20. Parents`curators` presence or absence to the marriage agrement

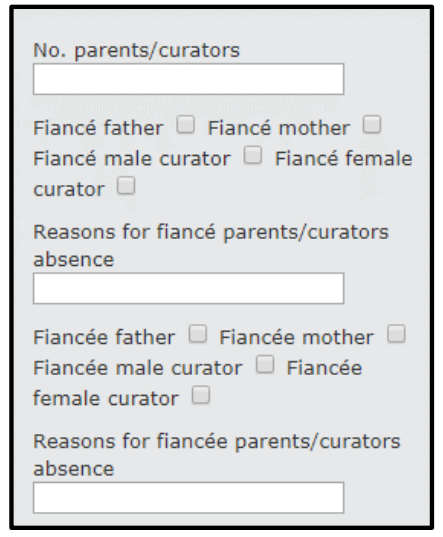

REASON FOR FIANCÉ/FIANCÉE PARENTS/CURATORS ABSENCE. If the parish register provides explanations about the absence from the betrothal of the parents/curators of the fiancé or fiancée (e.g. illness, death), those reasons should be filled in as recorded in the source.

FIANCÉ/FIANCÉE: MOTHER/FATHER/MALE CURATOR/FEMALE CURATOR FIRST NAME, LAST NAME, NICKNAME. The same rules apply as to the analogous fields from other forms about parents/fiancé/fiancée. 
FIANCÉ/FIANCÉE: MOTHER/FATHER/MALE CURATOR/FEMALE CURATOR LITERACY. The same rules apply as to the analogous fields recording the fiancé/fiancée's literacy.

FIANCÉ/FIANCÉE: MOTHER/FATHER/MALE CURATOR/FEMALE CURATOR ETHNICITY. The same rules apply as to the analogous fields recording ethnicity.

SOURCE OBSERVATIONS. If there are various remarks recorded in the source, this box will be ticked, and the respective remarks will be transcribed in this field

COMMENTS. If the data-entry operator has remarks of his/her own, this box will be ticked and the respective remarks will be recorded in the freshly opened field.

NO. OF RECORDED INDIVIDUALS. This is a normalization field, related to data management purposes. In it, the data-entry operator will record the total number of individuals mentioned in a record (fiancé, fiancée, parents, witnesses, etc.), except for the priest.

SOURCE. The code of the source will be selected from the drop-down list.

SOURCE PAGE. This field records the page number(s) from the parish register corresponding to the record transcribed in the database. In the particular case of the Betrothal registers, in which the information for each event is covering only one page, the number of the respective register sheet will be recorded, followed by $r$ or $v$ (recto or verso, e.g: $14 \mathrm{r}, 14 \mathrm{v})$. 


\section{Table 'MARRIAGES'}

Figure 21. Entry-form for table 'Marriages'

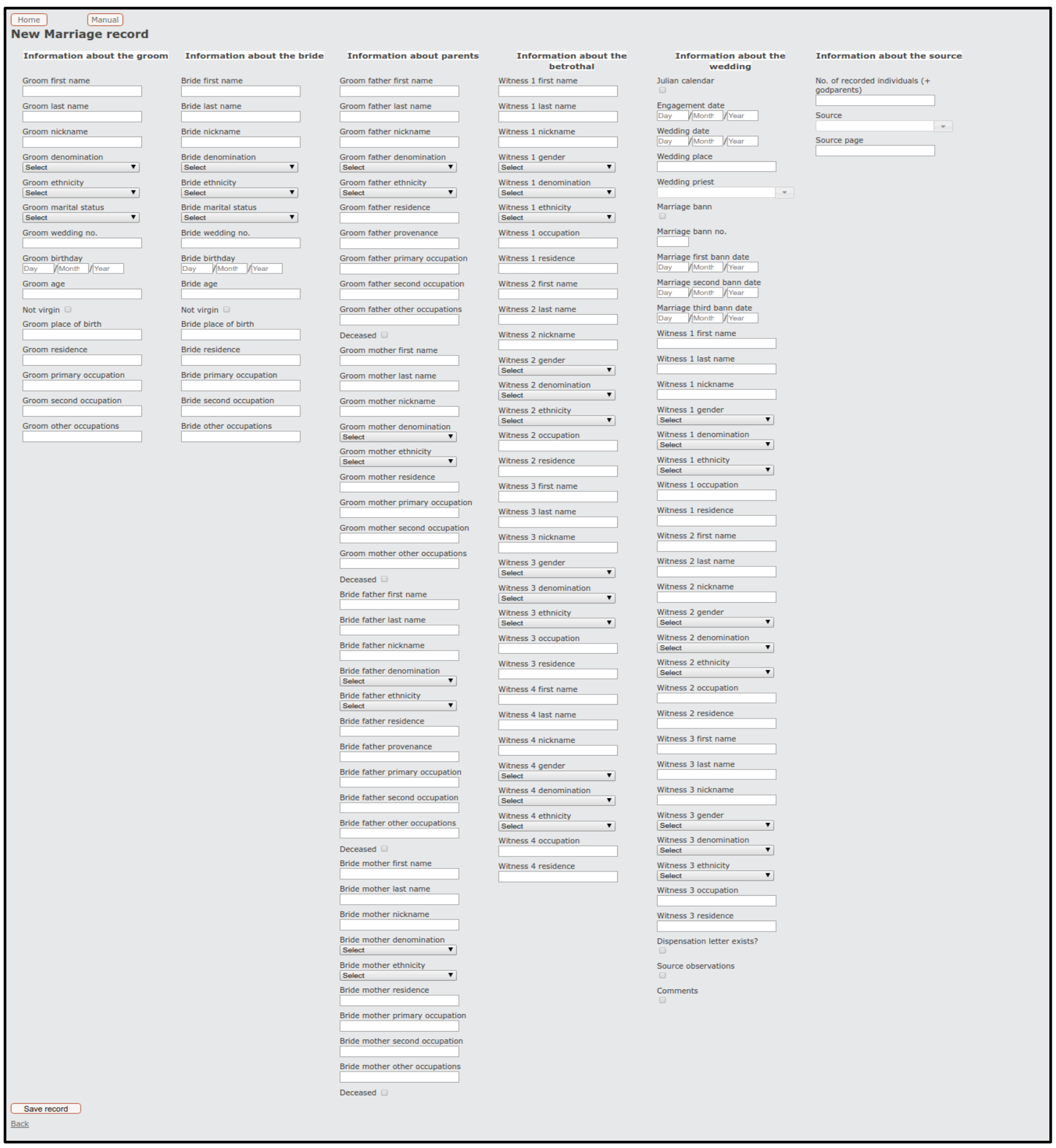

'Marriages' is the largest and most complex table of HPDT (see Figure 21). In the first version of the database it required more than 100 fields, due mainly to the numerous actors involved in this type of event and to the variety of information related to them. In the second version of the database, over 70 new fields were added, as the 
result of extending the data extraction process to new denominations (e.g. SECOND/THIRD OCCUPATION, ETHNICITY for each person involved in the event, a new set of individuals that were WITNESSES TO THE BETROTHAL, OBSERVATIONS made by the priest in the primary source). In the case of godparents, the large number of pairs sometimes involved - up to six pairs in one case - made it necessary to employ a soluton similar to the one for the 'Births' and migrate the information concerning the godparents to a separate table. In the latter, each pair is linked to the original event through the record ID from the table 'Marriages'.

\section{A. INFORMATION ON THE BRIDE AND GROOM}

GROOM/BRIDE FIRST NAME, LAST NAME, NICKNAME. Follows the same rules as the similar fields regarding the newborn, parents, fiancé, fiancée, etc.

GROOM/BRIDE DENOMINATION. Follows the same rules as the similar fields regarding the newborn, parents, fiancé, fiancée, etc.

GROOM/BRIDE ETHNICITY. Follows the same rules as the similar fields regarding the newborn, parents, fiancé, fiancée, etc, etc.

GROOM/BRIDE MARITAL STATUS. If the source indicates the marital status of the groom/bride, the appropriate value from the drop-down list should be selected (Figure 22).

Figure 22. Groom Marital Status

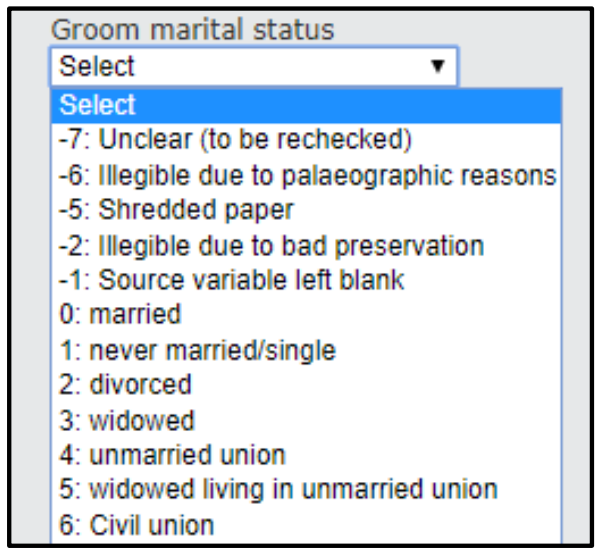

In practice, three possible situations can be encountered:

a. there are table headings for this type of information in the parish register and the information is actually recorded into the original source;

b. there are no table headings for this type of information in the original source, but the use of explicit terminology associated with the 'never married/single' situation allows this option to be selected. The following terms are associated with the 'never married/single' status: 
- RO: fată, fecior, fată în păr, copilă, june, jună;

- HU: ifjú, legény, leány, hajadon, kiasasszony (k. a.), úrfi, kiskorú gyermek, nőtelen, fia, leánya;

- LA: domicella, coelebs, in capillis constituta, filius, filia, spurius, spuria, proles;

c. the source holds no information on the marital status of the groom/bride, in which case the implicit label 'Select' will be choosed.

GROOM/BRIDE WEDDING NO. If the source holds explicit and distinct information on the number of marriages the bride and groom registered before the current one, it should be recorded as such. If only one number is mentioned by the source (e.g. 2, 3 ), lacking details on which of the newlyweds registered the respective number of marriages, it should be recorded for both of them.

GROOM/BRIDE BIRTHDAY. To be filled in following the format day/month/year (dd/mm/yyyy), and only with information mentioned by the source. If part of the date is missing in the parish register, the respective fields shall not be filled in.

GROOM/BRIDE AGE. To be filled in according to the source information. If the complete age is mentioned, it will be transcribed by the formula 'ymwdmh' - the age in years, months, weeks, days, hours (e.g. 28y3m5w12d6h).

NOT VIRGIN. To be ticked only if explicitly mentioned by the source.

GROOM/BRIDE GENDER. The same rules apply as to the similar fields in the tables 'Births' and 'Betrothals'.

GROOM/BRIDE PLACE OF BIRTH. The same rules apply as to the similar fields in the tables 'Births' and 'Betrothals'

GROOM/BRIDE RESIDENCE. The same rules apply as to the similar fields in the tables 'Births' and 'Betrothals'

GROOM/BRIDE OCCUPATION. The same rules apply as to the similar fields in the tables 'Births' and 'Betrothals'.

\section{B. INFORMATION ON THE PARENTS}

GROOM FATHER / MOTHER \& BRIDE FATHER/MOTHER FIRST NAME, LAST NAME, NICKNAME. The same rules apply as to the similar fields in the tables 'Births' and 'Betrothals'.

GROOM FATHER / MOTHER \& BRIDE FATHER/MOTHER GENDER. The same rules apply as to the similar fields in the tables 'Births' and 'Betrothals'. 
GROOM FATHER / MOTHER \& BRIDE FATHER/MOTHER DENOMINATION. The same rules apply as to the similar fields in the tables 'Births' and 'Betrothals'.

GROOM FATHER / MOTHER \& BRIDE FATHER/MOTHER ETHNICITY. The same rules apply as to the similar fields in the tables 'Births' and 'Betrothals'.

GROOM FATHER/MOTHER \& BRIDE FATHER/MOTHER OCCUPATION The same rules apply as to the similar fields in the tables 'Births' and 'Betrothals'.

GROOM FATHER/MOTHER \& BRIDE FATHER/MOTHER RESIDENCE The same rules apply as to the similar fields in the tables 'Births' and 'Betrothals'.

GROOM FATHER / MOTHER \& BRIDE FATHER / MOTHER DECEASED. To be ticked only if information is explicitely recorded in the source. In some cases, only one of the parents is recorded as deceased, in which case, only the respective box should be ticked (see below Figure 23).

Figure 23. Marking of the deceased parent

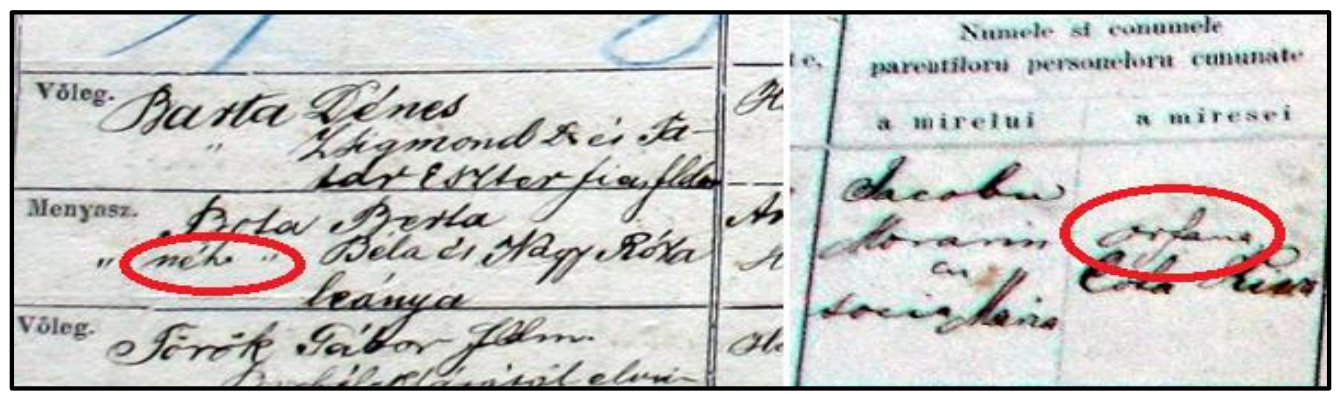

In the picture above, on the left hand side, the mention néh[ai] placed before the name of the bride's father requires the box DECEASED to be ticked for the respective person. In the picture on the right hand side, the mention orfan followed by the bride's mother's name requires the same action.

Important specifications regarding sections $C$ (Information about the Betrothal) and $D$ (information about the wedding) below. Both sections contain reference to the people acting as witnesses to the betrothal, respectively the wedding. The data-entry operator must be careful at all times to correctly identify the type of witnesses the information from the source refers to, and if there are any doubts in this regard, she/he should ask for a second opinion before proceeding with the data-entry activities. Also, if the same witnesses appear in both cases, they shall be recorded in both sections and shall be counted as multiple persons. E.g., if the same two persons act as witnesses upon betrothal and wedding, they shall be recorded in both sections, with complete information, and shall be counted as four witnesses. 


\section{INFORMATION ABOUT THE BETROTHAL}

WITNESS 1, 2, 3 \& 4 FIRST NAME, LAST NAME, NICKNAME. The same rules apply as to the similar fields in the tables 'Births' and 'Betrothals'.

WITNESS 1, 2, 3 \& 4 GENDER. The same rules apply as to the similar fields in the tables 'Births' and 'Betrothals'.

WITNESS 1, 2, 3 \& 4 DENOMINATION. The same rules apply as to the similar fields in the tables 'Births' and 'Betrothals'.

WITNESS 1, 2, 3 \& 4 ETHNICITY. The same rules apply as to the similar fields in the tables 'Births' and 'Betrothals'.

WITNESS 1, 2, 3 \& 4 OCCUPATION. The same rules apply as to the similar fields in the tables 'Births' and 'Betrothals'.

WITNESS 1, 2, 3 \& 4 RESIDENCE. The same rules apply as to the similar fields in the tables 'Births' and 'Betrothals'.

\section{INFORMATION ON MARRIAGE}

JULIAN CALENDAR. The same rules apply as to the similar fields in the tables 'Births' and 'Betrothals'.

ENGAGEMENT/WEDDING DATE. Register the engagement, respectively the wedding date. To be filled in following the format day $/ \mathrm{month} / \mathrm{year}(\mathrm{dd} / \mathrm{mm} / \mathrm{yyyy})$, and only with information mentioned by the source. If part of the date is missing in the parish register, the respective fields shall not be filled in.

WEDDING PLACE. The same rules apply as to the similar fields in the tables 'Births' and 'Betrothals'.

WEDDING PRIEST. The same rules apply as to the similar fields in the tables 'Births' and 'Betrothals'.

MARRIAGE BANN. Tick if the source contains any information regarding the marriage banns, namely the public announcement in the church of the future marriage - either the dates of the banns or the fact that were announced without any other specification (see Figure 24 below). 
Figure 24. Marriage banns

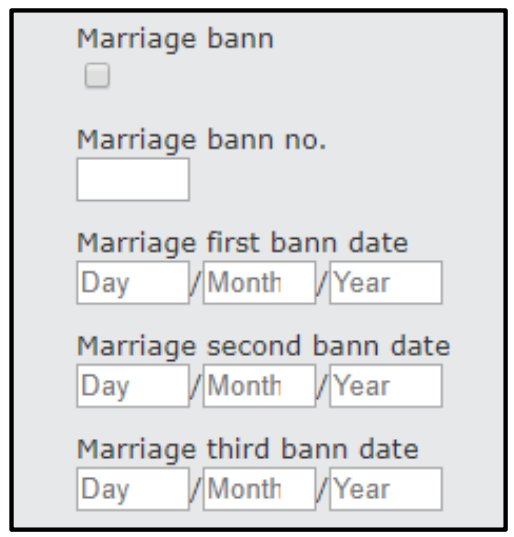

MARRIAGE BANN NO. Write the number of banns specified in the source, even if their dates are not recorded.

DATE OF MARRIAGE BANNS. To be filled in following the format day/month/year (dd/mm/yyyy), and only with information mentioned by the source. If part of the date is missing in the parish register, the respective fields shall not be filled in, but if the month or the year it's not repeated because it's the same, they can be filled in.

WITNESS 1, 2 \& 3 FIRST NAME, LAST NAME, NICKNAME. The same rules apply as to the similar fields regarding parents, godparents, etc (see Figure 25 below). If there are more than three witnesses (either for marriage or for engagement), the others should be recorded within the field SOURCE OBSERVATIONS. If the source mentiones collective witnesses (e.g. 'the entire village', 'the neighbours') these shall be registered in SOURCE OBSERVATIONS.

WITNESS 1, 2 \& 3 GENDER. The same rules apply as to the similar fields in the tables 'Births' and 'Betrothals'.

WITNESS 1, 2 \& 3 DENOMINATION. The same rules apply as to the similar fields regarding parents, godparents, etc.

WITNESS 1, 2 \& 3 ETHNICITY. The same rules apply as to the similar fields regarding parents, godparents, etc.

WITNESS 1, 2 \& 3 OCCUPATION. The same rules apply as to the similar fields regarding parents, godparents, etc.

WITNESS 1, 2 \& 3 RESIDENCE. The same rules apply as to the similar fields regarding parents, godparents, etc. 
Figure 25. Witness 1 information

\begin{tabular}{|l|}
\hline Witness 1 first name \\
\hline Witness 1 last name \\
\hline \\
Witness 1 nickname \\
\hline Witness 1 gender \\
\hline Select \\
Witness 1 denomination \\
\hline Select \\
Witness 1 ethnicity \\
Select \\
Witness 1 occupation \\
\hline \\
\hline Witness 1 residence \\
\hline
\end{tabular}

DISPENSATION LETTER EXISTS? If there is a dispensation letter mentioned, tick and write the date of granting the dispensation in the field DISPENSATION DATE, and its type in the field DISPENSATION TYPE. In case the dispensation type is not mentioned within the dropdown list, tick 'Other Type of Dispensation' and fill in its type at COMMENTS (see Figure 26 below).

Figure 26. Dispensation letters

\begin{tabular}{|c|c|c|}
\hline \multirow{4}{*}{$\begin{array}{l}\text { Dispensation letter exists? } \\
\text { Dispensation date }\end{array}$} & & \multirow{12}{*}{$\begin{array}{l}\text { Select } \\
\text {-7: Dispensation type not mentioned } \\
\text {-6: Illegible due to palaeographic reasons } \\
\text {-5: Shredded paper } \\
-2 \text { : Illegible due to bad preservation } \\
\text {-1: Source variable left blank } \\
\text { 1: Dispensation from unspecified family relation } \\
\text { 100: Dispensation from the impediment of consanguinity } \\
\text { 200: Dispensation from the impediment of affinity } \\
\text { 300: Dispensation from the impediment of age } \\
\text { 400: Dispensation from the impediment of mourning } \\
\text { 500: Dispensation from the impediment of sacred time } \\
600 \text { : Dispensation from the impediment of disparity of worship or disparity of cult } \\
\text { 700: Dispensation from the impediment of mixed marriage (ethnicity) } \\
\text { 800: Dispensation of marriage banns } \\
900 \text { : Other dispensation letters }\end{array}$} \\
\hline & & \\
\hline & & \\
\hline & & \\
\hline Day $\sqrt{\text { Month }} /$ Year & & \\
\hline \multicolumn{2}{|l|}{ Type of dispensation } & \\
\hline Select & $\mathbf{v}$ & \\
\hline \multicolumn{2}{|l|}{ Other dispensations } & \\
\hline \multicolumn{2}{|l|}{ Type of dispensation } & \\
\hline Select & $\mathbf{r}$ & \\
\hline \multicolumn{2}{|l|}{ Type of dispensation } & \\
\hline & 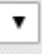 & \\
\hline
\end{tabular}

SOURCE OBSERVATIONS. If there are mentions or observations in the source, tick this box and copy precisely the respective observation in the freshly opened field. If additional explanations from the data-entry operator are required, they shall be recorded between square brackets. 
COMMENTS. If the data-entry operator has its own observations related to the whole entry (others than those mentioned above, related to the particular observations extracted from the source), the box should be ticked and the observations recorded in the freshly opened field.

\section{E. INFORMATION ON THE SOURCE}

NO. OF RECORDED INDIVIDUALS. This is a normalization field, related to data management purposes. In it, the data-entry operator will record the total number of individuals mentioned in a record (groom, bride, parents, witnesses, etc.), except for the priest.

SOURCE. The code of the source will be selected from the drop-down list.

SOURCE PAGE. This field records the page number(s) from the parish register corresponding to the record transcribed in the database. 
44 I.Bolovan, B.Crăciun, D.Covaci, L.Dumănescu, E.C.Holom, D.Mârza, A.C.Lumezeanu

\section{Table 'DEATHS’}

Figure 27. Entry-form for table 'Deaths'

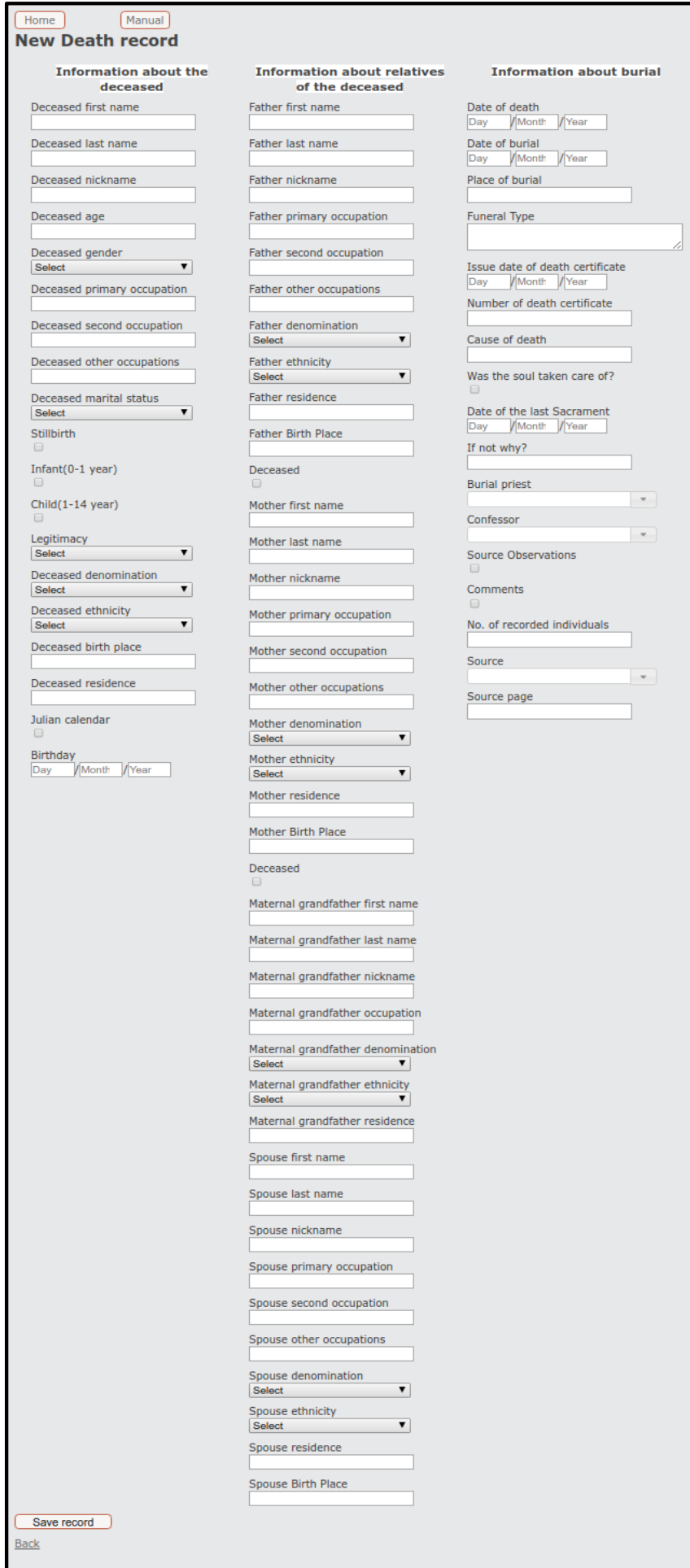

The entry-form for table 'Deaths' is divided into three sections of fields, corresponding to the information regarding the deceased, his/her relatives (parents, 
husband/wife) and the event itself. A separate table allows the registration of relatives of the deceased, other than the ones included in the current form.

\section{A. INFORMATION ABOUT THE DECEASED}

DECEASED FIRST NAME, LAST NAME, NICKNAME. The same rules apply as to the similar fields from the tables 'Births', 'Betrothals', and 'Marriages'. The maiden name of a deceased married female, name change of the deceased, introduced by 'alias' or other similar phrasings if mentioned by the source should also be recorded in the field NICKNAME with the symbol '\#' in front of them. The same field will be used for recording the formula 'Junior' or 'Senior', when mentioned by the source.

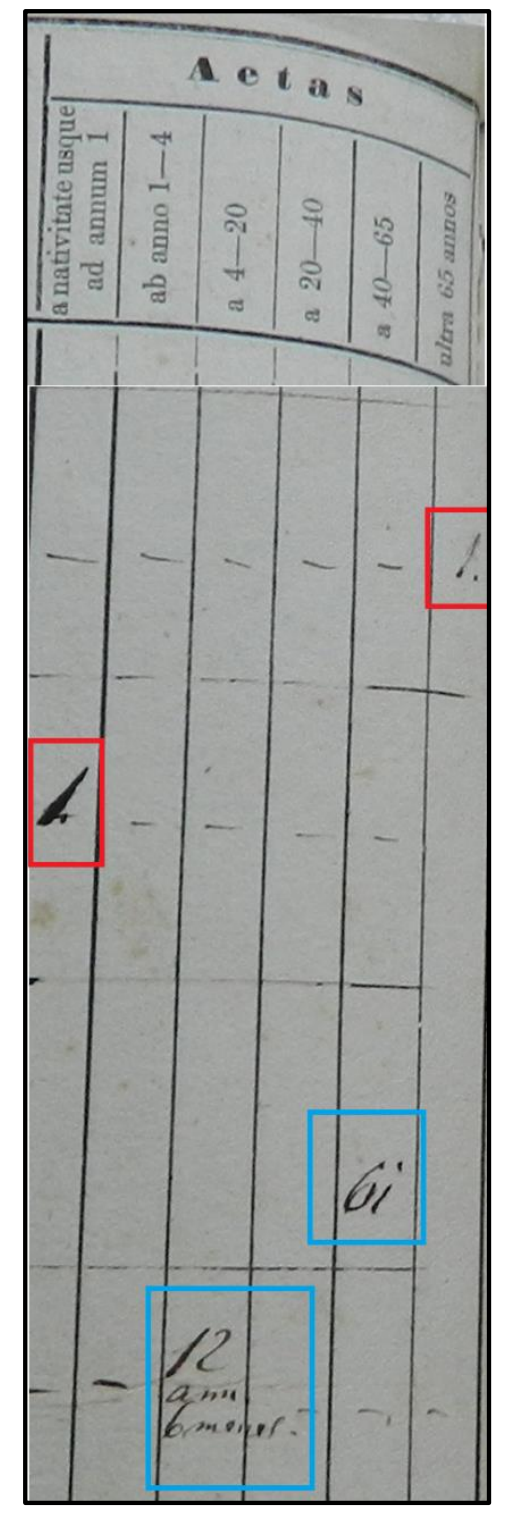

DECEASED AGE. To be filled in according to the source information (See Figures 28a and 28b). If the complete age is mentioned, it will be transcribed by the formula 'ymwdmh' - the age in years, months, weeks, days, hours (e.g. $28 \mathrm{y} 3 \mathrm{~m} 5 \mathrm{w} 12 \mathrm{~d} 6 \mathrm{~h}$ ). For the children that died in their first day of life, the source component of the database will record the original registration of hours or minutes, which in the standardized component will be round up to a day, in order to facilitate the analysis. Some parish registers, mainly RomanCatholic ones, have dedicated fields for age groups (e.g. under one year old, between one and four, four and 20, 20 and 40,40 and 65 , and over 65 years old. The proper fill in of the data thus rested with the priest; some members of the clergy filled the exact age in the respective field, while others simply ticked the field of the deceased's age group.

Figure 28a. A Roman-Catholic parish register with a header that groups ages.

The first two entries in the source, placed in a red square, are basic markings of the age group's field. In the database, the first entry, corresponding to 'over 65 years' has been filled in as 'cca65y' due to the lack of further information; the second one corresponds to the group 'under one year old', but it was accompanied by a mention in the 'Comments' field of the parish register pointing that the deceased was four months old. The last two entries, in blue squares, have the exact age recorded in the age group fields, which was also transcribed in the database (Figure 28b). 
Figure 28b. Age records of the deceased

\begin{tabular}{|ll|l|}
\hline Anna & Marosi & cca65y \\
Ioannes & Pál & $4 \mathrm{~m}$ \\
Franciscus & Antalfi & $61 \mathrm{y}$ \\
Aloysius & Mihály & $12 \mathrm{y} 6 \mathrm{~m}$ \\
\hline
\end{tabular}

DECEASED GENDER. The same rules apply as to the similar fields in the tables 'Births', 'Betrothals' and 'Marriages'. The gender is being inferred according to the name of the deceased person. When this is not possible because the name is ascribed to males and females alike (e.g. Sava or Todosie, for the Romanian ethnics) option 10 ('Both') should be selected. If the name is illegible due to various paleographic reasons or bad preservation of the register the respective code should be selected from the dropdown list.

DECEASED OCCUPATION (PRIMARY / SECOND / OTHER). The same rules apply as to the similar fields in the tables 'Births', 'Betrothals' and 'Marriages'.

DECEASED MARITAL STATUS. If the source mentiones the marital status of the deceased, the appropriate value from the drop-down list should be selected.

STILLBIRTH, INFANT (0-1 YEARS) and CHILD (1-14 YEARS) are boxes that need to be ticked according to the situation and age of the deceased. They function as normalization fields, allowing an easier grouping of children deaths for analytical purposes, and the separate recording of stillbirths explicitly mentioned by the sources (see Figure 29 below). Their reason of creation in the first place is related to the tipological variety of age recording in the parish registers, which raised filtering issues when transcribed in the sources component of the database.

Figure 29. Checkboxes for infants/children

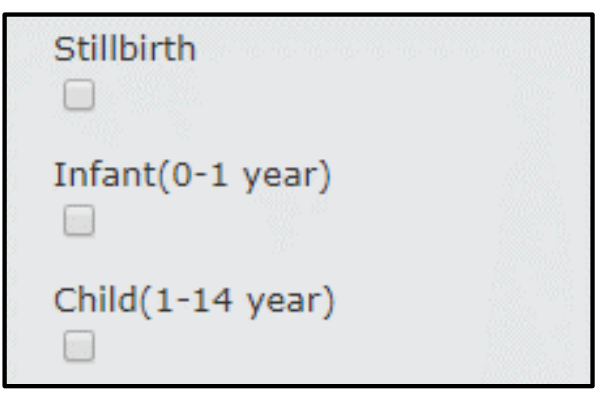

LEGITIMACY. The same rules apply as to the similar fields in the table 'Births'.

DECEASED DENOMINATION. The same rules apply as to the similar fields in the tables 'Births', 'Betrothals', and 'Marriages'. 
DECEASED ETHNICITY. The same rules apply as to the similar fields in the tables 'Births', 'Betrothals', and 'Marriages'.

DECEASED BIRTH PLACE. The same rules apply as to the similar fields in the tables 'Births', 'Betrothals', and 'Marriages'.

DECEASED RESIDENCE. The same rules apply as to the similar fields in the tables 'Births', 'Betrothals', and 'Marriages'.

JULIAN CALENDAR The same rules apply as to the similar fields in the tables 'Births', 'Betrothals', and 'Marriages'.

BIRTHDAY. To be filled in following the format day/month/year (dd/mm/yyyy), and only with information mentioned by the source. If part of the date is missing in the parish register, the respective fields shall not be filled in.

\section{B. INFORMATION ABOUT RELATIVES OF THE DECEASED}

FATHER / MOTHER / MATERNAL GRANDFATHER / SPOUSE FIRST NAME, LAST NAME, NICKNAME. The same rules apply as to the similar fields from the tables 'Births', 'Betrothals', and 'Marriages'. Many of the deceased were children, therefore the names of their parents were mentioned explicitly; in the Orthodox or GreekCatholic registers there are also cases in which the name of the mother of the deceased child was missing, since the name of the father was considered sufficient for identifying her/him. The maternal grandfather's name was recorded for illegitimate children, because it was the other relevant male for identifying the deceased child.

FATHER / MOTHER / MATERNAL GRANDFATHER / SPOUSE OCCUPATION (PRIMARY / SECOND / OTHER). The same rules apply as to the similar fields from the tables 'Births', 'Betrothals', and 'Marriages'.

FATHER / MOTHER / MATERNAL GRANDFATHER / SPOUSE DENOMINATION. The same rules apply as to the similar fields from the tables 'Births', 'Betrothals', and 'Marriages'.

FATHER / MOTHER / MATERNAL GRANDFATHER / SPOUSE ETHNICITY. The same rules apply as to the similar fields from the tables 'Births', 'Betrothals', and 'Marriages'.

FATHER / MOTHER / MATERNAL GRANDFATHER / SPOUSE RESIDENCE. The same rules apply as to the similar fields from the tables 'Births', 'Betrothals', and 'Marriages'. 
FATHER / MOTHER / MATERNAL GRANDFATHER / SPOUSE BIRTH PLACE. The same rules apply as to the similar fields from the tables 'Births', 'Betrothals', and 'Marriages'.

DECEASED (FATHER / MOTHER) it's a box that needs to be ticked if the respective detail it's specifically mentioned by the sources.

\section{INFORMATION ABOUT BURIAL}

DATE OF DEATH/BURIAL. To be filled in following the format day/month/year (dd/mm/yyyy), and only with information mentioned by the source. If part of the date is missing in the parish register, the respective fields shall not be filled in.

PLACE OF BURIAL. The same rules apply as to the similar fields in the tables 'Births', 'Betrothals' and 'Marriages'. It usually includes both the name of the cemetery and of the locality where the burial took place.

CAUSE OF DEATH. To be filled in using the exact information in the source, if recorded. Many registers lack this information, because the cause of death was supposed to be established only after an official investigation from the death inspector (Rotar 2012). 'Ordinary death' or 'natural death' are widely used, covering an extended range of ages, from infants to old people, a possible sign that the official death inquiry either was not performed, or its results were not registered by the local priest. Towards the end of the nineteenth century however, the recording of the causes of death took place more thoroughly. In the example below (See Figure 30), the field 'Cause of death' records a 'natural' passing.

Figure 30. Cause of death in sources

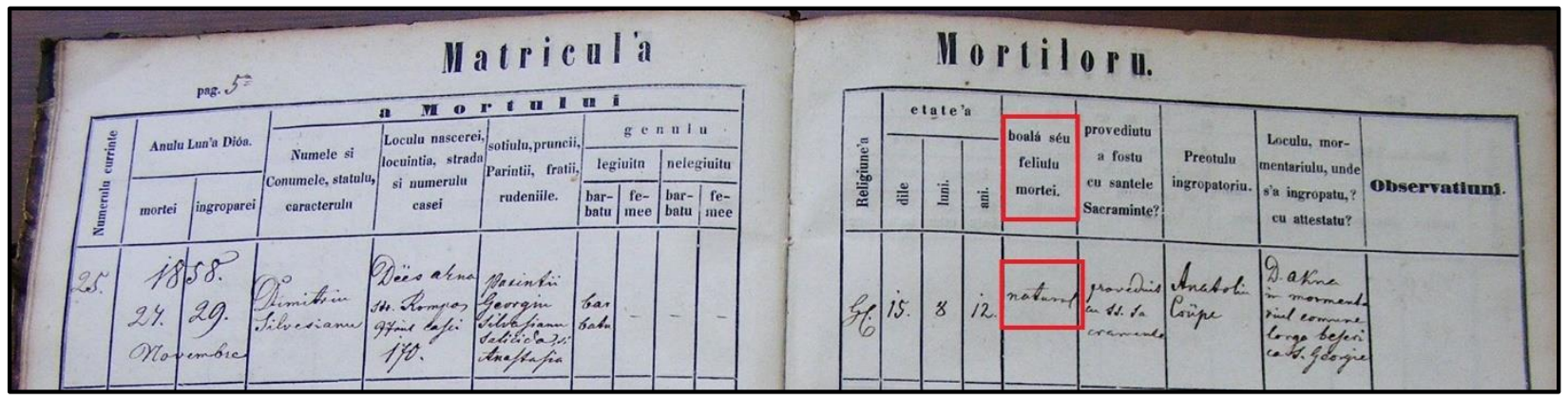

WAS THE SOUL TAKEN CARE OF? If the source mentions that the dying person was offered the last rites, this box must be ticked.

DATE OF THE LAST SACRAMENT. To be filled in following the format $\mathrm{day} / \mathrm{month} /$ year ( $\mathrm{dd} / \mathrm{mm} / \mathrm{yyyy})$, and only if this information is specifically mentioned by the source. 
IF NOT WHY? To be filled in with the reason why the dying person was not offered the last rites, if mentioned by the source. The last rites were usually skipped in case of children, of people who died a violent or sudden death, or if the priest was not residing in the parish. In most of the cases, the information pertaining to this field was not filled in by the person responsible with keeping the registers.

BURIAL PRIEST. The same rules apply as to the similar fields in the tables 'Births', 'Betrothals' and 'Marriages'.

CONFESSOR. To be filled in only if the name of the confessor is explicitly mentioned within the registers. The confessor's name can be selected from the same dropdown list as the priests', since most of the time they were the same person, namely the local priest.

SOURCE OBSERVATIONS. The same rules apply as to the similar fields in the tables 'Births', 'Betrothals' and 'Marriages'. In the example below (see Figure 31), the place of death is explicitely mentioned ('Spitalul din Turda' / 'Turda Hospital'), a relatively rare information. Other mentions in the source, not related directly to the recording of vital events, should also be transcribed in this field (e.g. the mention of a canonical visitation from the dean or the bishop, who examined the accuracy of data recording in the parish registers, and undersigned their findings).

Figure 31. Source observations

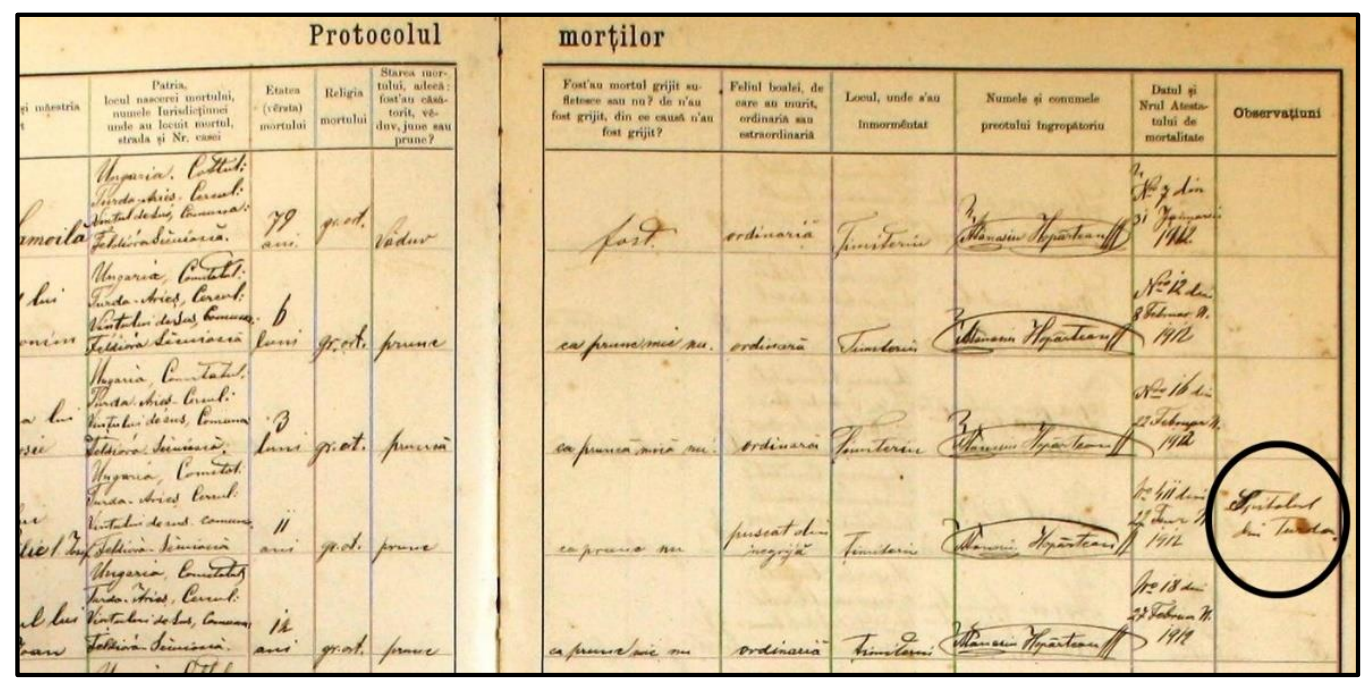

COMMENTS. The same rules apply as to the similar fields in the tables 'Births', 'Betrothals' and 'Marriages'.

NO. OF REGISTERED INDIVIDUALS. The same rules apply as to the similar fields in the tables 'Births', 'Betrothals' and 'Marriages'. 
SOURCE. The same rules apply as to the similar fields in the tables 'Births', 'Betrothals' and 'Marriages'.

SOURCE PAGE. The same rules apply as to the similar fields in the tables 'Births', 'Betrothals' and 'Marriages'. 


\section{Table 'DECEASED RELATIVES'}

Figure 32. Entry-form for table 'Deceased relatives'

\begin{tabular}{|l|}
\hline New Record \\
Death ID \\
\hline Select \\
\hline Firstname \\
\hline \\
\hline Lastname \\
\hline Nickname \\
\hline Role \\
\hline Select \\
Remark \\
\hline \\
\hline Save \\
\hline Back \\
\hline
\end{tabular}

The mention by the death registers of other relatives than father, mother, maternal grandfather or spouse of the deceased led to the employment of this secondary table, linked to table 'Deaths'.

DEATH ID. From this dropdown table the data-entry operator chooses the ID of the entry in the 'Deaths' table corresponding to the currently recorded relative of the deceased.

FIRSTNAME / LASTNAME / NICKNAME. The same rules apply as to the similar fields from the tables 'Births', 'Betrothals', 'Marriages', and 'Deaths'.

ROLE. From this dropdown table the data-entry operator chooses from a list of predefined kin relationships. The list includes the children and children-in-law of the deceased, brothers, concubine, etc. but also the 'Unknown' option, for those cases in which the parish register does not clearly state the relationship between the deceased and the respective person. If the source mentiones a kin relationship not present in the list, the latter should be appended before completing the entry. (See Figure 33). 
Figure 33. Role table

\begin{tabular}{|l|}
\hline Role \\
\hline Select \\
\hline Select \\
\hline Daughter \\
Son \\
Brother \\
Sister \\
Son-in-law \\
Daughter-in-law \\
1st wife \\
Concubine \\
Nephew \\
Maternal grandmother \\
Unknown \\
\hline
\end{tabular}

REMARKS. Further data in the original source about the status, ethnicity or occupation of the relative (e.g. 'spinster', 'Gypsy', 'married', 'illegitimate') should be recorded in this field. 


\section{Table 'GODPARENTS'}

Figure 34. Entry-form for table 'Godparents'

\begin{tabular}{|c|c|c|c|}
\hline $\begin{array}{c}\text { Editing Godparents } \\
\text { Person role }\end{array}$ & Information about godfather & $\begin{array}{l}\text { Information about } \\
\text { godmother }\end{array}$ & Information about event \\
\hline Baptism Witness & $\begin{array}{l}\text { Godfather first name } \\
\text { Miclos }\end{array}$ & $\begin{array}{l}\text { Godmother first name } \\
\text { Maria }\end{array}$ & Birth \\
\hline \multirow[t]{7}{*}{ Confirmation Godparent } & $\begin{array}{l}\text { Godfather last name } \\
\text { Ola }\end{array}$ & $\begin{array}{l}\text { Godmother last name } \\
\text { Borbely }\end{array}$ & Marriage \\
\hline & Godfather nickname & Godmother nickname & Observations \\
\hline & $\begin{array}{l}\text { Godfather denomination } \\
\text { Select }\end{array}$ & $\begin{array}{l}\text { Godmother denomination } \\
\text { Select }\end{array}$ & \\
\hline & $\begin{array}{l}\text { Godfather ethnicity } \\
\text { Select }\end{array}$ & $\begin{array}{l}\text { Godmother ethnicity } \\
\text { Select }\end{array}$ & \\
\hline & Godfather occupation & Godmother occupation & \\
\hline & Godfather residence & Godmother residence & \\
\hline & & $\begin{array}{l}\text { Select relation between godparents } \\
\text { Select }\end{array}$ & \\
\hline Save record & & & \\
\hline I Back & & & \\
\hline
\end{tabular}

The fifth main table of HPDT is dedicated to the spiritual parents of the baptized children, of the newly confirmed persons, or of the young couple who perfomed the marriage sacrament. The entry-form is divided into four sections, dedicated to the key role of the persons in the events, general information on godparents / wittnesses, and the leading event in which they acted in this capacity.

\section{A. PERSON ROLE}

This section only refers to those instances not fully covered by the fourth section (Information about the event), i.e. baptism witness and Confirmation godparent.

BAPTISM WITNESS. The respective box should be ticked only if the recorded person(s) play(s) the role of witness at the moment of baptism, situation occurring in the case of Jewish, Reformed (Calvinist) and Lutheran denominations.

CONFIRMATION GODPARENT. The respective box should be ticked only if the recorded person(s) acted as godparents in a children confirmation rite; mainly the case of Reformed (Calvinist) and Roman-catholic denominations. 


\section{B. INFORMATION ABOUT GODFATHER/GODMOTHER}

GODFATHER/GODMOTHER FIRST NAME, LAST NAME, NICKNAME. The same rules apply as to the similar fields from the tables 'Births', 'Betrothals', 'Marriages', and 'Deaths'.

GODFATHER/GODMOTHER DENOMINATION. The same rules apply as to the similar fields from the tables 'Births', 'Betrothals', 'Marriages', and 'Deaths'.

GODFATHER/GODMOTHER ETHNICITY. The same rules apply as to the similar fields from the tables 'Births', 'Betrothals', 'Marriages', and 'Deaths'. Under no circumstances should denomination be considerend an argument for inferring ethnicity, if the latter is not explicitely mentioned by the source.

GODFATHER/GODMOTHER OCCUPATION. The same rules apply as to the similar fields from the tables 'Births', 'Betrothals', 'Marriages', and 'Deaths'.

GODFATHER/GODMOTHER RESIDENCE. The same rules apply as to the similar fields from the tables 'Births', 'Betrothals', 'Marriages', and 'Deaths'.

SELECT RELATION BETWEEN GODPARENTS. In some cases, the parish registers bear accurate mention on the liaison between the two godparents. In such cases, the respective relation should be selected from the dropdown list (e.g. wife, daughter, mother, sister, parent-in-law, grandmother, cousin) (See Figure 35).

Figure 35

\begin{tabular}{|l|} 
Select relation between godparents \\
\begin{tabular}{|l|}
\hline Select \\
\hline Select \\
\hline Wife \\
Daughter \\
Mother \\
Sister \\
Parent-in-law \\
Grandmother \\
Cousin \\
\hline
\end{tabular} \\
\hline
\end{tabular}




\section{INFORMATION ABOUT EVENT}

BIRTH/MARRIAGE. The data entry operator chooses the type of event in which the recorded persons took part by cheking the appropriate box, and then selects from the opening dropdown list the ID of the entry in the 'Births' or 'Marriage' tables corresponding to the event. In cases involving Jewish, Reformed (Calvinist) and Lutheran denominations, the appropriate box in the first section of the data-entry form should also be ticked (see above A. Person role. BAPTISM WITNESS).

If more than one pair of godparents / witnesses is recorded by the source as attending the event, a new entry in the table 'Godparents' should be made for each pair or single godparent / witness following the first pair.

OBSERVATIONS. If the data-entry operator has special remarks to make (problems with the source, mistakes made by the priests, etc), they should be entered in the field which opens after the box is being ticked. 


\section{Table 'CONVERTS'}

Figure 36. Entry-form for table 'Converts'

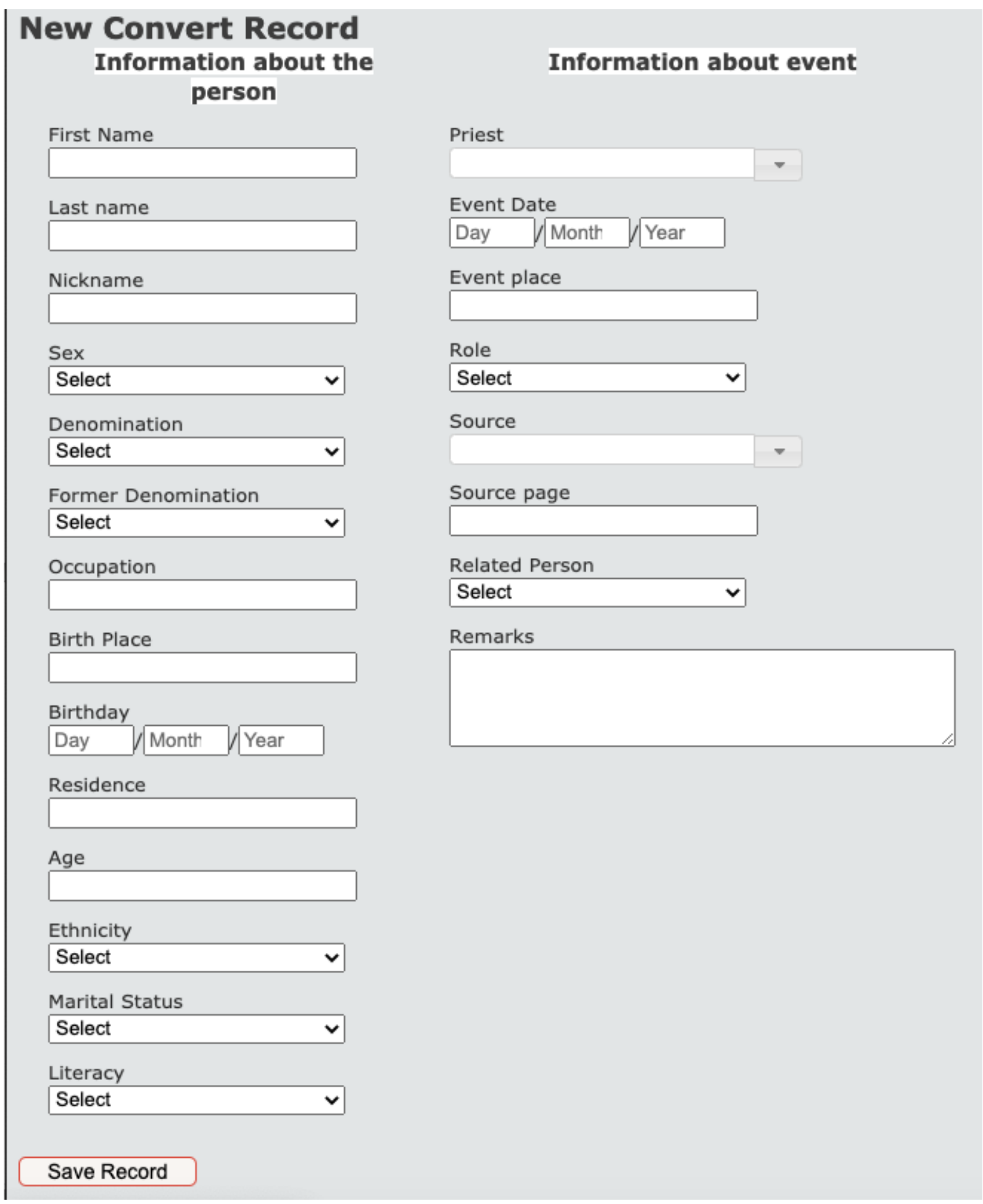

Table 'Converts' was built in order to accommodate information from the church documents dedicated specifically to this event. Such sources are few in numbers, and the involved persons are usually also mentioned in other types of vital registration, yet 
the recording of their non-converted relatives (spouses, children, parents) can prove helpful in the process of family reconstitution.

CONVERT'S FIRSTNAME / LASTNAME / NICKNAME. The same rules apply as to the similar fields from the tables 'Births', 'Betrothals', 'Marriages', and 'Deaths'.

CONVERT'S SEX. The same rules apply as to the similar fields in the tables 'Births', 'Betrothals', 'Marriages', and 'Deaths', including the cases in which the sex cannot be inferred due to onomastic or palaeographic reasons.

CONVERT'S DENOMINATION. The new denomination of the convert person, namely the denomination of the parish register in which the conversion was recorded, will be selected from the drop down list.

CONVERT'S FORMER DENOMINATION. The former denomination of the convert person, which is usually explicitely mentioned, will be selected from the drop down list. If the source has failed to register this detail, the default option 'Select' should not be changed.

CONVERT'S OCCUPATION. The same rules apply as to the similar fields in the tables 'Births', 'Betrothals', 'Marriages', and 'Deaths'

CONVERT'S BIRTHPLACE. To be filled in only if explicitely mentioned in the source as the birthplace (and not the residence) of the convert person.

CONVERT'S BIRTHDAY. To be filled in following the format day/month/year (dd/mm/yyyy), and only with information mentioned by the source. If part of the date is missing in the parish register, the respective fields shall not be filled in.

CONVERT'S RESIDENCE. To be filled in exactly as registered in the source, with abbreviations, accents and accented characters following the same rules detailed for tables 'Births', 'Betrothals', 'Marriages', and 'Deaths'.

CONVERT'S AGE. To be filled in according to the source information. If the complete age is mentioned, it will be transcribed by the formula 'ymwdmh' - the age in years, months, weeks, days, hours (e.g. 28y3m5w12d6h).

CONVERT'S ETHNICITY. If the source explicitely mentiones the ethnicity, the appropriate value shall be selected from the drop-down menu. Under no circumstances the denomination of the parish register should be taken into account as a criterion for inferring and filling in ethnicity. 
CONVERT'S MARITAL STATUS. If the source mentiones the marital status of the convert person, the appropriate value from the drop-down list should be selected.

CONVET'S LITERACY. The same rules apply as to the similar fields in table 'Betrothals'.

PRIEST. The corresponding name will be selected from the drop-down list. The selection follows the same rules as for the other tables.

EVENT DATE. To be filled in following the format day/month/year (dd/mm/yyyy), and only with information mentioned by the source. If part of the date is missing in the parish register, the respective fields shall not be filled in.

EVENT PLACE. The same rules apply as to the field CONVERT'S RESIDENCE and the other similar fields in the database.

ROLE. If the recorded person is the convert, the respective role should be selected from the drop down list. In case family members or wittnesses are being mentioned in the source in relation to the convert (not necesarilly converts themselves), their role should be selected from the drop down list. In the latter cases, information regarding the denomination should not be filled in, unless explicitely mentioned by the source. The person can be manually linked with the convert by means of the field RELATED PERSON (see below).

SOURCE. The code of the source will be selected from the drop-down list.

SOURCE PAGE. This field records the page number(s) from the parish register corresponding to the record transcribed in the database. It follows the same rules as for all similar fields in the database.

RELATED PERSON. This field provides the means of manually linking a nonconverted person with a convert, by selecting the name of the latter from a drop down list and creating a link between the two records.

REMARKS. If the data-entry operator has remarks of his/her own, they will be recorded in this field. 


\section{Table 'CONFIRMATION'}

Figure 37. Entry-form for table 'Confirmation'

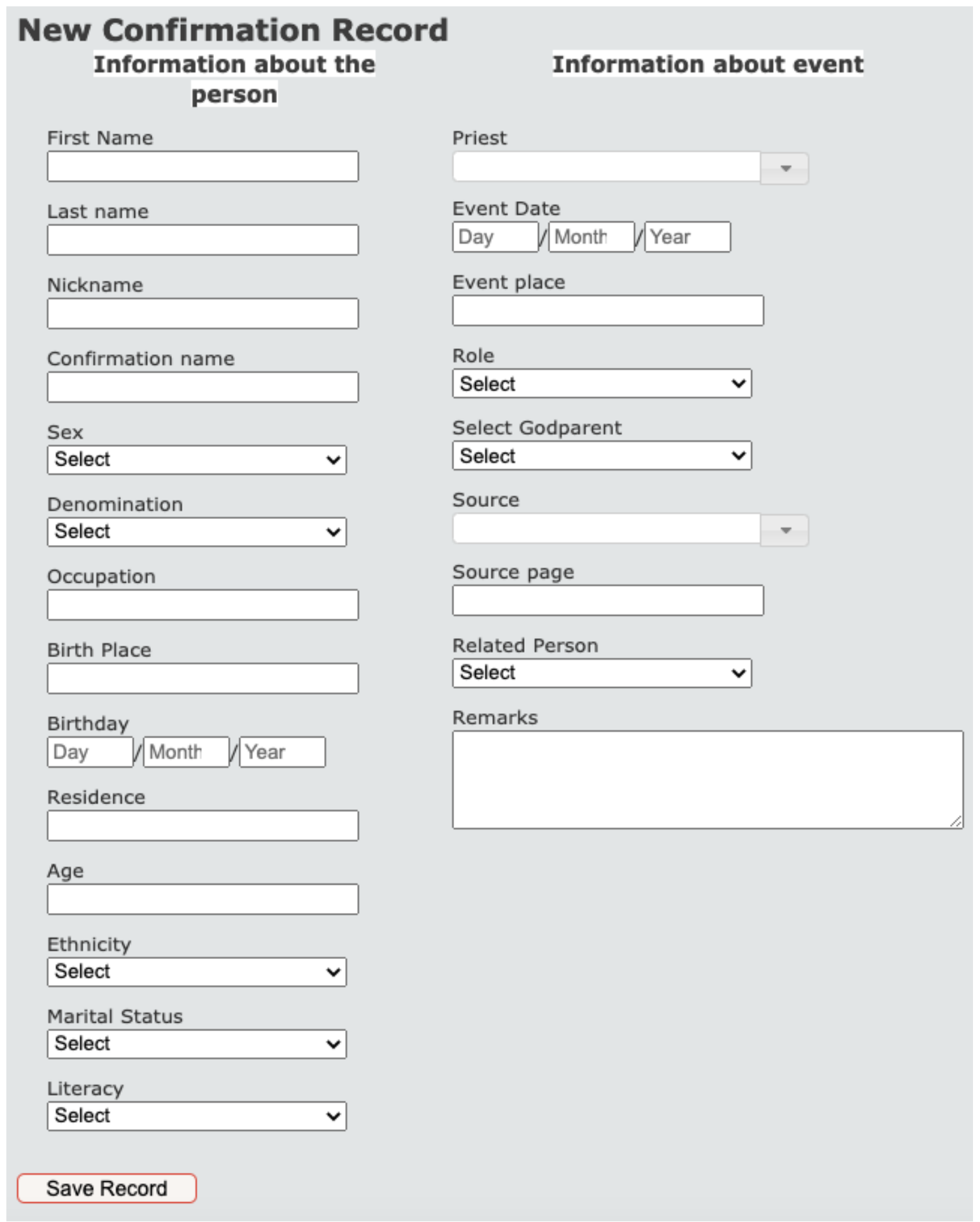

Table 'Confirmation' hosts information extracted from the church registers dedicated to this rite of passage. The numbers of such sources is low and the involved persons are usually also mentioned in other types of vital registration. Similar to the 
above mentioned case of the table 'Converts', the information can prove helpful in establishing family or social ties (the latter through godparenting).

CONFIRMED PERSON'S FIRSTNAME / LASTNAME / NICKNAME. The same rules apply as to the similar fields from the tables 'Births', 'Betrothals', 'Marriages', and 'Deaths'.

CONFIRMED PERSON'S SEX. The same rules apply as to the similar fields in the previously detailed tables.

CONFIRMED PERSON'S DENOMINATION. The denomination of the parish register in which the confirmation was recorded will be selected from the drop down list.

CONFIRMED PERSON'S OCCUPATION. The same rules apply as to the similar fields in the previously detailed tables.

CONFIRMED PERSON'S BIRTH PLACE. To be filled in only if explicitely mentioned in the source as the birthplace (and not the residence) of the confirmed person.

CONFIRMED PERSON'S BIRTHDAY. To be filled in following the format day/month/year (dd/mm/yyyy), and only with information mentioned by the source. If part of the date is missing in the parish register, the respective fields shall not be filled in.

CONFIRMED PERSON'S RESIDENCE. To be filled in exactly as registered in the source, with abbreviations, accents and accented characters following the same rules detailed for the other tables.

CONFIRMED PERSON'S AGE. To be filled in according to the source information. If the complete age is mentioned, it will be transcribed by the formula 'ymwdmh' - the age in years, months, weeks, days, hours (e.g. 28y3m5w12d6h).

CONFIRMED PERSON'S ETHNICITY. If the source explicitely mentiones the ethnicity, the appropriate value shall be selected from the drop-down menu. Under no circumstances the denomination of the parish register should be taken into account as a criterion for inferring and filling in ethnicity.

CONFIRMED PERSON'S MARITAL STATUS. If the source mentiones the marital status of the confirmed person, the appropriate value from the drop-down list should be selected.

CONFIRMED PERSON'S LITERACY. To be filled in according to the contents of the source. If the signature of the confirmed person is present, option 'can write name' 
should be selected. If the letter ' $X$ ', or a cross appears in the original source instead of the signature, the option 'cannot write name' should be selected. If there is no signature, nor other sign of written aknowledgement of the document's contents, no selection should be made. See also the details and figures from table 'Betrothals'.

PRIEST. The corresponding name will be selected from the drop-down list. The selection follows the same rules as for the tables 'Births', 'Betrothals', 'Marriages', and 'Deaths'.

EVENT DATE. To be filled in following the format day/month/year (dd/mm/yyyy), and only with information mentioned by the source. If part of the date is missing in the parish register, the respective fields shall not be filled in.

EVENT PLACE. The same rules apply as to the field CONFIRMED PERSON'S RESIDENCE and the other similar fields in tables 'Births', 'Betrothals', 'Marriages', and 'Deaths'.

ROLE. If the recorded person is the confirmed person, the respective role should be selected from the drop down list. In case the recorded person is a family member or a tutor, mentioned in the source in relation to the confirmed person, his/her role should be selected from the drop down list. In the latter cases, information regarding the denomination should not be filled in, unless explicitely mentioned by the source. The family members/tutors can be manually linked with the confirmed person by means of the field RELATED PERSON (see below).

GODPARENT. The name of the confirmation godparent(s) mentioned in the source will be selected from the drop down list. This implies that the respective godparents have already been recorded in the dedicated table (see above table 'Godparents').

SOURCE. The code of the source will be selected from the drop-down list.

SOURCE PAGE. This field records the page number(s) from the parish register corresponding to the record transcribed in the database. It follows the same rules as for the tables 'Births', 'Betrothals', 'Marriages', and 'Deaths'.

RELATED PERSON. This field provides the means of manually linking a family member or tutor with a confirmed person, by selecting the name of the latter from a drop down list and creating a link between the two records.

REMARKS. If the data-entry operator has remarks of his/her own, they will be recorded in this field. 


\section{Table 'NAME CHANGE'}

Figure 38. Entry-form for table 'Name Change'

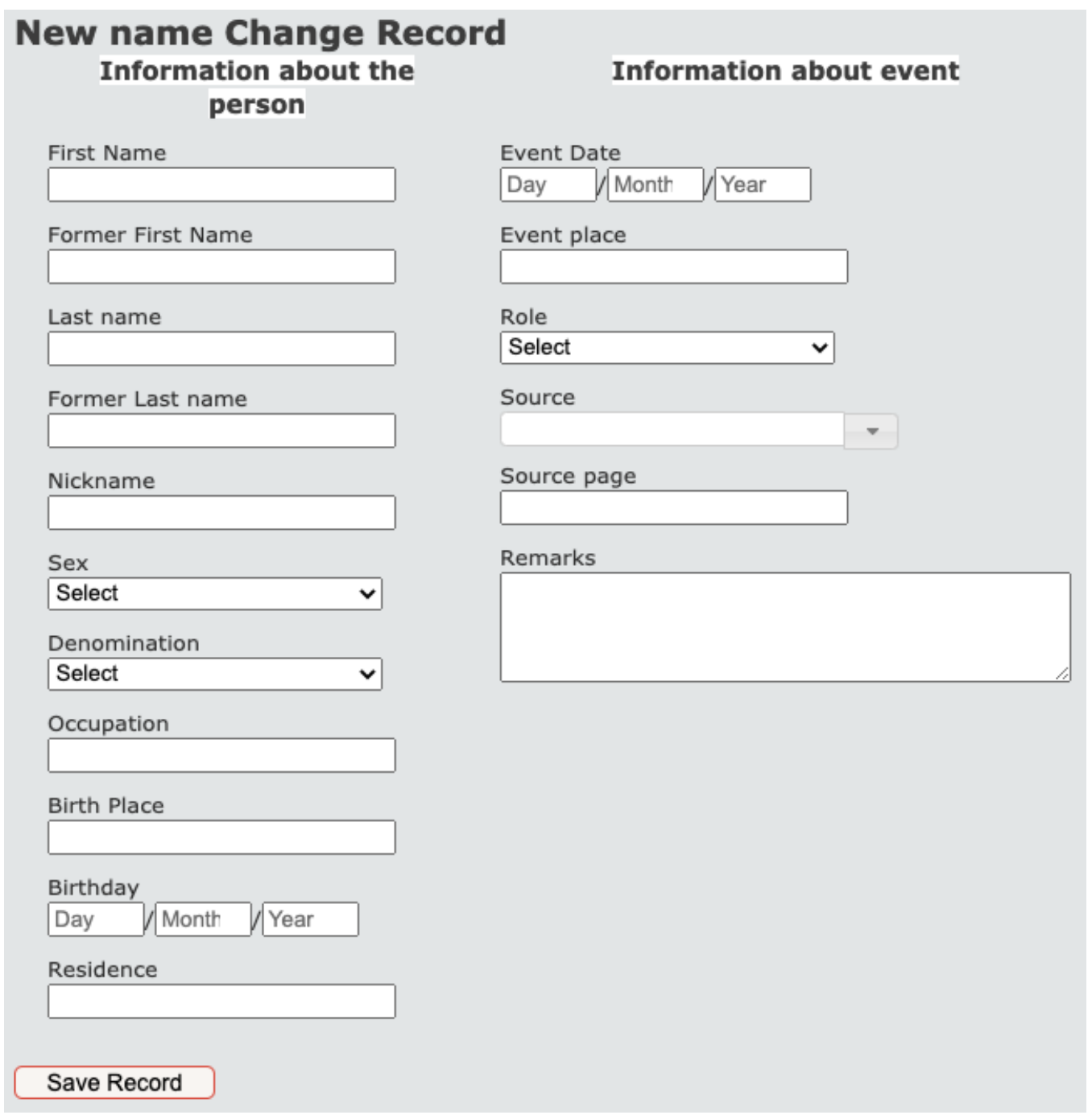

From the eighteenth to early twentieth century, it was not unsual for people to change their names, either by choosing a whole different surname, making an onomastic addition on genealogical basis, or simply adopting another language version of both the first and last name (usually the official language of the state). Over 20.000 name changes were officially allowed by the Ministry of Interior in Hungary (including Transylvania) between 1867 and 1918, sometimes, but not always, in the framework of the official Magyarisation policies (see Farkas 2012 for an annotated bibliography of the subject in international languages; see also Figures 39a-c below). Such name changes were sometimes recorded in the parish registers, as additional information to the standard fields, or in the 'Observations' field of the source. In order for this type of information to be easily accessible for linkage purposes, the database developers have chosen to use a dedicated entry form. 
Figure 39a. Name change record (Jewish to Hungarian)

\begin{tabular}{|c|c|}
\hline Person information & Event information \\
\hline First Name: Hermán & Event Date: //1907 \\
\hline Former First Name: Hermán & Event place: \\
\hline Last Name: Horváth & Role: \\
\hline Former Last Name: Hirsch & Source: 140001 \\
\hline Nickname: & Source place: Nușfalău \\
\hline Sex: 1 & Source page: $43 r$ \\
\hline $\begin{array}{l}\text { Denomination: } \\
\text { Occupation: } \\
\text { Birth Place: Doh } \\
\text { Birthday: // }\end{array}$ & $\begin{array}{l}\text { Remarks: } \% \% \text { A járás fszbiró } 1877- \\
907 \text { rg. sz. a velem közölt } 37019 \text { or. } \\
\text { m. K. B. m. ur rendelet szerint e } \\
\text { rovatban levő család név "Horvath" ra } \\
\text { átváltoztatott. \%\% [Schimbare de } \\
\text { nume] }\end{array}$ \\
\hline \multirow[t]{3}{*}{ Residence: } & Entry author: \\
\hline & Modified by: \\
\hline & Entry date: $13 / 05 / 201607: 26$ \\
\hline
\end{tabular}

Figure 39b. Name change record (Romanian to Hungarian)

\begin{tabular}{|c|c|}
\hline Person information & Event information \\
\hline First Name: Carolu & Event Date: $28 / 12 / 1914$ \\
\hline Former First Name: Carolu & Event place: \\
\hline Last Name: Vásárhelyi & Role: \\
\hline Former Last Name: Popa & Source: 010037 \\
\hline Nickname: & Source place: Ocna-Mureș \\
\hline Sex: 1 & Source page: $7 v-8 r$ \\
\hline $\begin{array}{l}\text { Denomination: } \\
\text { Occupation: } \\
\text { Birth Place: Muresiu-Uiora }\end{array}$ & $\begin{array}{l}\text { Remarks: Conumele de Popa cu } \\
\text { facultatea ministerului de interne de } \\
\text { dta } 17 \text { nov. } 1914 \text { Nr. } 1857071900 \text { si } \\
\text { la schimbat in "Vásárhelyi" } 28 / \text { XI } \\
\text { [semnătura] B Popu parochu. }\end{array}$ \\
\hline Birthday: 29/1/1881 & Entry author: \\
\hline & \\
\hline & Modified by: \\
\hline & Entry date: $23 / 02 / 2017$ 11:20 \\
\hline
\end{tabular}


Figure 39c. Name change record (Hungarian to Romanian)

\begin{tabular}{|c|c|}
\hline Person information & Event information \\
\hline First Name: Theodorus & Event Date: //1919 \\
\hline Former First Name: Theodorus & Event place: \\
\hline Last Name: Pădurean & Role: \\
\hline Former Last Name: Erdős & Source: 010040 \\
\hline Nickname: & Source place: Ocna Mures \\
\hline Sex: 1 & Source page: $12 v-13 r$ \\
\hline $\begin{array}{l}\text { Denomination: } \\
\text { Occupation: } \\
\text { Birth Place: }\end{array}$ & $\begin{array}{l}\text { Remarks: } \% \% 12183 / 1919 \text { conumele } \\
\text { de Erdős sa permisu să se schimbe } \\
\text { respective prein numele original } \\
\text { familiar Pădurean. Emil Pop, } \\
\text { paroch\%\%. }\end{array}$ \\
\hline Birthday: // & Entry author: \\
\hline \multirow[t]{3}{*}{ Residence: } & \\
\hline & Modified by: \\
\hline & Entry date: $03 / 05 / 201708: 23$ \\
\hline
\end{tabular}

FIRSTNAME / LASTNAME / NICKNAME. The current (new) names of the person will be filled in this fields. Same rules apply as to the similar fields from the tables 'Births', 'Betrothals', 'Marriages', and 'Deaths'.

FORMER FIRSTNAME / FORMER LASTNAME. The former names of the person will be filled in this fields. Same rules apply as to the similar fields from the tables 'Births', 'Betrothals', 'Marriages', and 'Deaths'.

SEX. The same rules apply as to the similar fields in the previously detailed tables.

DENOMINATION. The denomination of the parish register in which the confirmation was recorded will be selected from the drop down list.

OCCUPATION. The same rules apply as to the similar fields in the previously detailed tables.

BIRTH PLACE. To be filled in only if explicitely mentioned in the source as the birthplace (and not the residence) of the confirmed person.

BIRTHDAY. To be filled in following the format day/month/year (dd/mm/yyyy), and only with information mentioned by the source. If part of the date is missing in the parish register, the respective fields shall not be filled in.

RESIDENCE. To be filled in exactly as registered in the source, with abbreviations, accents and accented characters following the same rules detailed for the other tables. 
EVENT DATE. To be filled in following the format day $/$ month/year (dd/mm/yyyy), and only with information mentioned by the source. If part of the date is missing in the parish register, the respective fields shall not be filled in.

EVENT PLACE. The same rules apply as to the field CONFIRMED PERSON'S RESIDENCE and the other similar fields in previously detailed tables.

ROLE. If the recorded person is mentioned as having a specific role (e.g. child, witness), it shall be chosen from the drop down accordingly.

SOURCE. The code of the source will be selected from the drop-down list.

SOURCE PAGE. This field records the page number(s) from the parish register corresponding to the record transcribed in the database. It follows the same rules as for the previously detailed tables.

REMARKS. If the data-entry operator has remarks of his/her own, they will be recorded in this field. 


\section{Table 'PRIEST'}

By performing the baptism and the matrimonial ceremony, as well as administering the last rites and conducting the burial service, church representatives were basically mentioned in every single record of the original sources, and the name of the same person can be encountered from several to several hundred times, under multiple onomastical variants. In order to eliminate redundancy and to ensure a corect registration, the records of priests, rabbis and other persons officiating religious services were normalized. The table "Priest" thus provides a separate unique record for each person who conducted in his official capacity as church representative a number of events registered in a church document.

Figure 40. Entry form for table 'Priest'

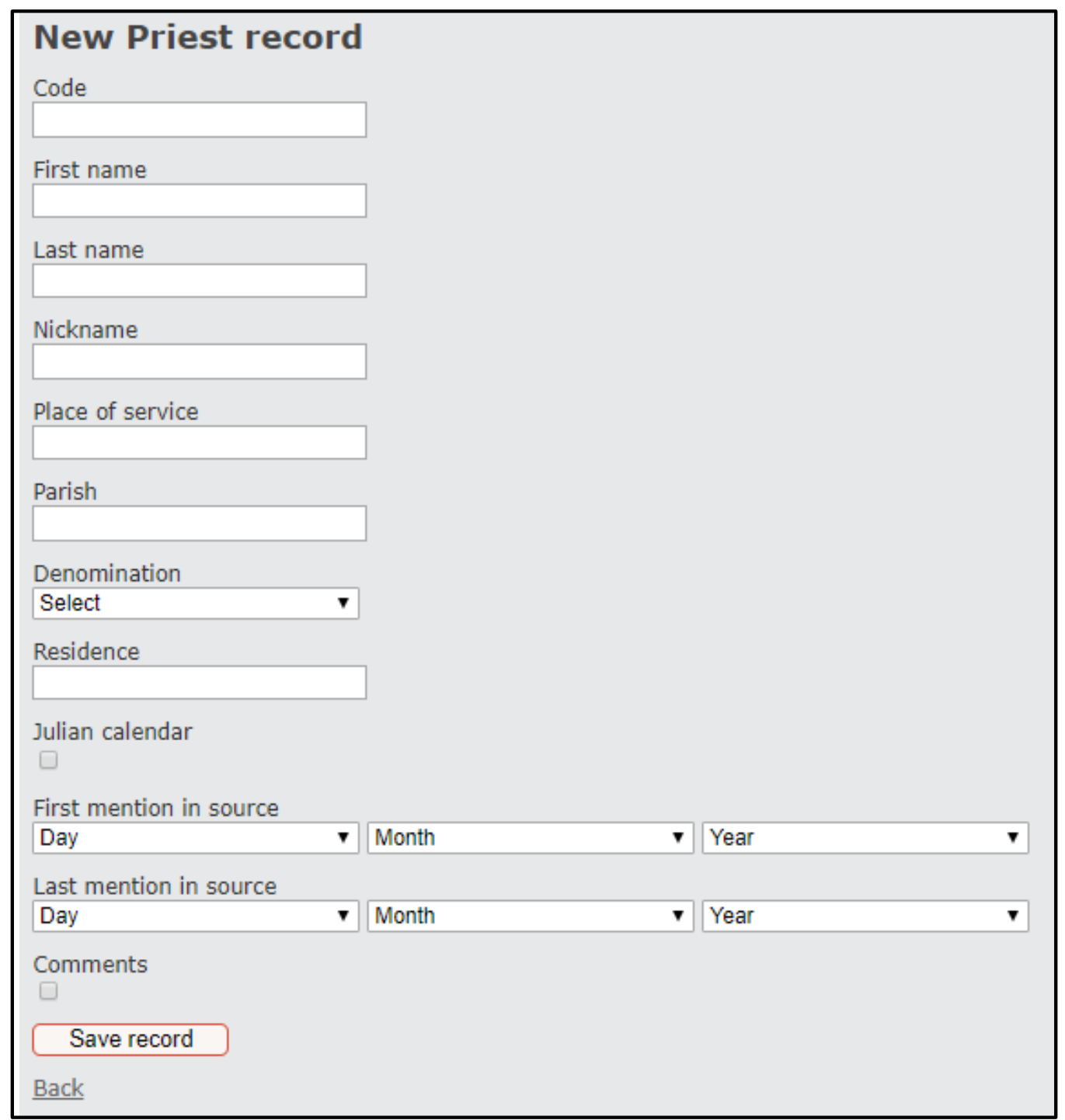

CODE. A unique six-digit code will be manually assigned to each combination priest / place of service (e.g. 000001). Thus, a priest mentioned in several locations will be recorded multiple times in the table 'Priest', each time with a different place of service 
and receiving a different code for each occurrence. The data-entry operators will choose from the PRIEST drop down list the code and name corresponding to the priest and the locality in which he served when recording the event (code, full name and place name are all visibile in the drop-down list).

Example: the priest Eulampie Negrea is mentioned in the localities RăzboieniCetate and Cucerdea. He is recorded twice in the table 'Priests' table, with different codes. The data entry operator will choose the code corresponding to the locality in which the priest has performed the recorded church-related service (see Figure 41).

Figure 41. Drop-down search with the name of the priest

\section{Priest eulampie \\ 000001: Eulampie\&Eulampiu Negrea-- Războieni-Cetate 000250: Eulampie Negrea-- Cuceredea}

For Rabbis, the first digit of the code shall be replaced by the letter $\mathrm{R}$ (e.g. R00001).

If the person performing the baptism is a Christian, but not a priest, the code for 'Lay person' will be selected, and the letter 'L' will replace the first digit (e.g. L00001). This situation may occur at birth when, due to the physical weakness of the newborn, an emergency baptism was performed by the midwife or another present member of the family, in order to save his/her soul.

In the case of Jewish registers, the person performing the circumcision, the Mohel, will receive a similar code, starting with the letter 'M' (e.g. M00001).

FIRST NAME, LAST NAME, NICKNAME. The same rules apply as to the similar fields from the previously detailed tables.

PLACE OF SERVICE. Same as the locality of the source.

PARISH. To be filled in only when multiple parishes of the same denomination exist in the same locality.

DENOMINATION. The same rules apply as to the similar fields from from the previously detailed tables.

RESIDENCE. To be filled in only if explicit information on the priest's residence is recorded in the source.

JULIAN CALENDAR. The same rules apply as to the similar fields from from the previously detailed tables. 
FIRST MENTION IN SOURCE. To be filled in following the format day/month/year (dd/mm/yyyy), and only with information mentioned by the source, marking the first appearance of the priest in the source for all the events counted in the respective register.

LAST MENTION IN SOURCE. The same rules apply as to the field FIRST MENTION IN SOURCE, now marking the last mention of the priest in the respective document(s).

COMMENTS. The same rules apply as to the similar fields from from the previously detailed tables.

For research and verification purposes, each record in the table 'Priest' allows the listing of all other records of individuals related to the services performed by the respective church representative (Figure 42). 
Figure 42. Listing of the events associated to a church personell code in HPDT

\begin{tabular}{|c|c|c|c|c|c|c|c|}
\hline \multicolumn{8}{|c|}{ Code: 001266} \\
\hline \multicolumn{8}{|c|}{ First name: Ieremias \& Hieremiasz \& Ieremia } \\
\hline \multicolumn{8}{|c|}{ Last name: Lokián } \\
\hline \multicolumn{8}{|c|}{ Nickname: } \\
\hline \multicolumn{8}{|c|}{ Place of service: Ocna Dej } \\
\hline \multicolumn{8}{|c|}{ Parish: Ocna Dej } \\
\hline \multicolumn{8}{|c|}{ Denomination: 6120} \\
\hline \multicolumn{8}{|c|}{ Residence: Nima } \\
\hline \multicolumn{8}{|c|}{ Julian calendar: false } \\
\hline \multicolumn{8}{|c|}{ First mention in source: $15 / 08 / 1857$} \\
\hline \multicolumn{8}{|c|}{ Last mention in source: $20 / 08 / 1863$} \\
\hline \multicolumn{8}{|c|}{ Comments: Ex delegatione Source 070056: 1862.10.02-1862.10.02 } \\
\hline \multicolumn{8}{|c|}{ Entry author: } \\
\hline \multicolumn{8}{|c|}{ Modified by: } \\
\hline \multicolumn{8}{|c|}{ Entry date: $28 / 11 / 2018$ 10:32 } \\
\hline No. crt. & Type & ID & First name & Last name & Nickname & Source code & Source page \\
\hline 1 & Birth & 65030 & Geiza & & & 070049 & $1 v-2 r$ \\
\hline 2 & Birth & 65039 & Ilona Albertina & Bodor & & 070049 & $2 v-3 r$ \\
\hline 3 & Birth & $\underline{65041}$ & $\begin{array}{l}\text { Anna\&Anna } \\
\text { Maria }\end{array}$ & Pap & & 070049 & $2 v-3 r$ \\
\hline 4 & Birth & 65043 & Georgius & Pap & & 070049 & $2 v-3 r$ \\
\hline 5 & Birth & 65044 & Alexander & Kolcza & & 070049 & $2 v-3 r$ \\
\hline 6 & Birth & 65045 & Anna Josepha & Kolcza & & 070049 & $2 v-3 r$ \\
\hline 7 & Birth & 65054 & Georgius & Pap & & 070049 & $4 v-5 r$ \\
\hline 8 & Birth & 65055 & Juliana & Pap & & 070049 & $4 v-5 r$ \\
\hline 9 & Birth & $\underline{65056}$ & Helena Bertha & Bodor & & 070049 & $4 v-5 r$ \\
\hline 10 & Birth & $\underline{65074}$ & $\begin{array}{l}\text { Janos } \\
\% \% \text { Arpad } \% \%\end{array}$ & Balintfy & & 070049 & $6 v-7 r$ \\
\hline 11 & Birth & $\underline{65075}$ & Ioannes & Pál & & 070049 & $6 v-7 r$ \\
\hline 12 & Birth & 65129 & Georgius & Pap & & 070049 & $7 v-8 r$ \\
\hline 13 & Marriage & $\underline{18767}$ & Nicolau & Prodanu & & 070056 & $10 v-11 r$ \\
\hline 14 & Death & 46837 & Michael & Endes & & 070049 & $1 v-2 r$ \\
\hline 15 & Death & 46839 & Georgius & Endes & & 070049 & $1 v-2 r$ \\
\hline 16 & Death & 46850 & Anna & Páp & & 070049 & $1 v-2 r$ \\
\hline 17 & Death & 46852 & Antonius & Birta & & 070049 & $1 v-2 r$ \\
\hline 18 & Death & $\overline{46861}$ & Anna Josepha & $\% \%$ Kolcza $\% \%$ & & 070049 & $2 v-3 r$ \\
\hline
\end{tabular}




\section{Table 'MIDWIFE'}

Figure 43. The entry form for table Midwife

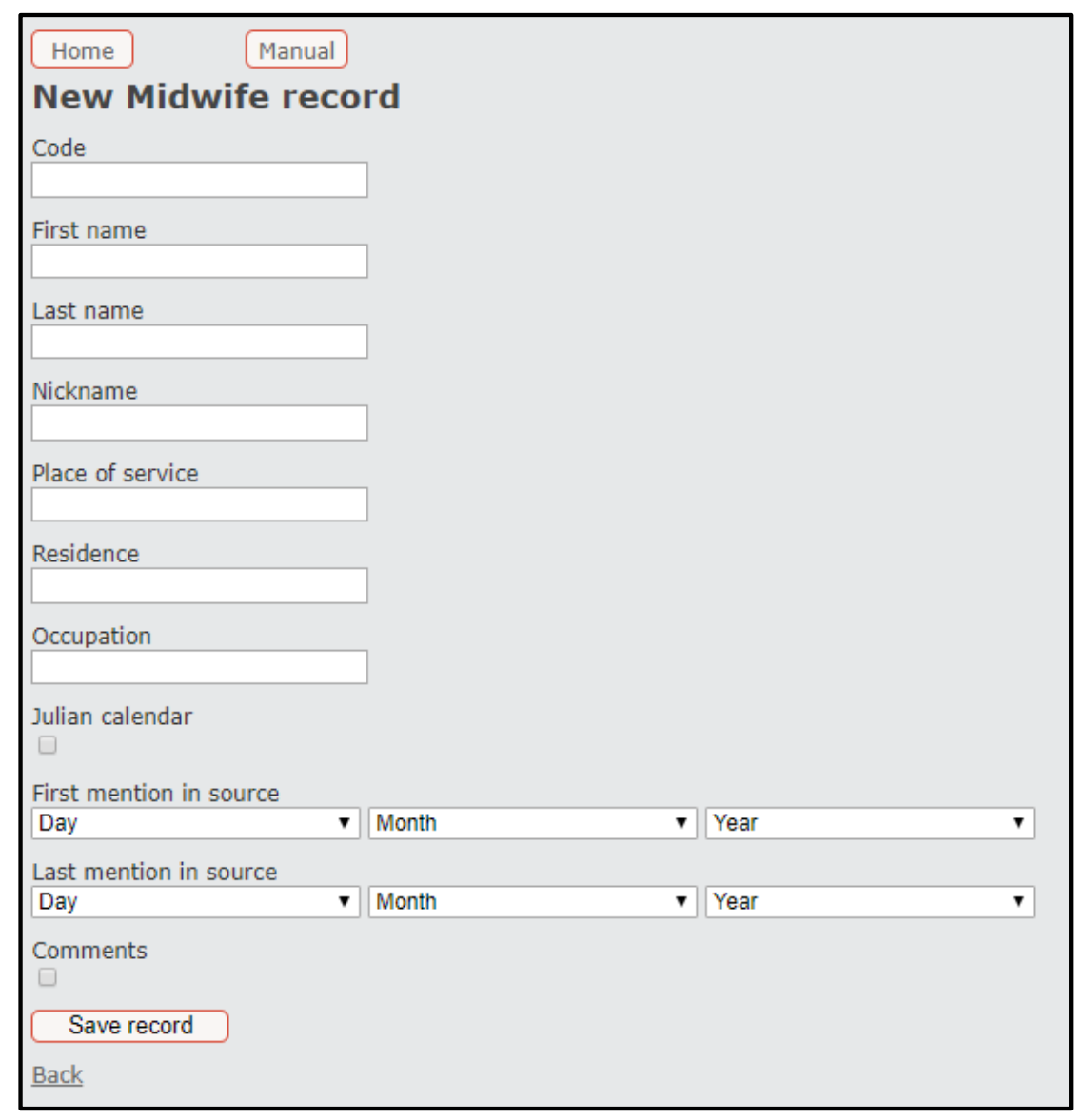

Table 'Midwife' was created out of similar reasons as table 'Priest' and follows the same principles.

CODE. A unique six-digit code code will be manually assigned to each combination midwife / place of service. Thus, a midwife mentioned in several locations will be recorded multiple times, each time with a different place of service and receiving a different code for each occurrence.

The data-entry operators will choose from the MIDWIFE drop down list the code and name corresponding to the midwife and the locality in which she served when recording the event (code, full name and place name are all visibile in the drop-down list - Figure 44). 
Figure 44

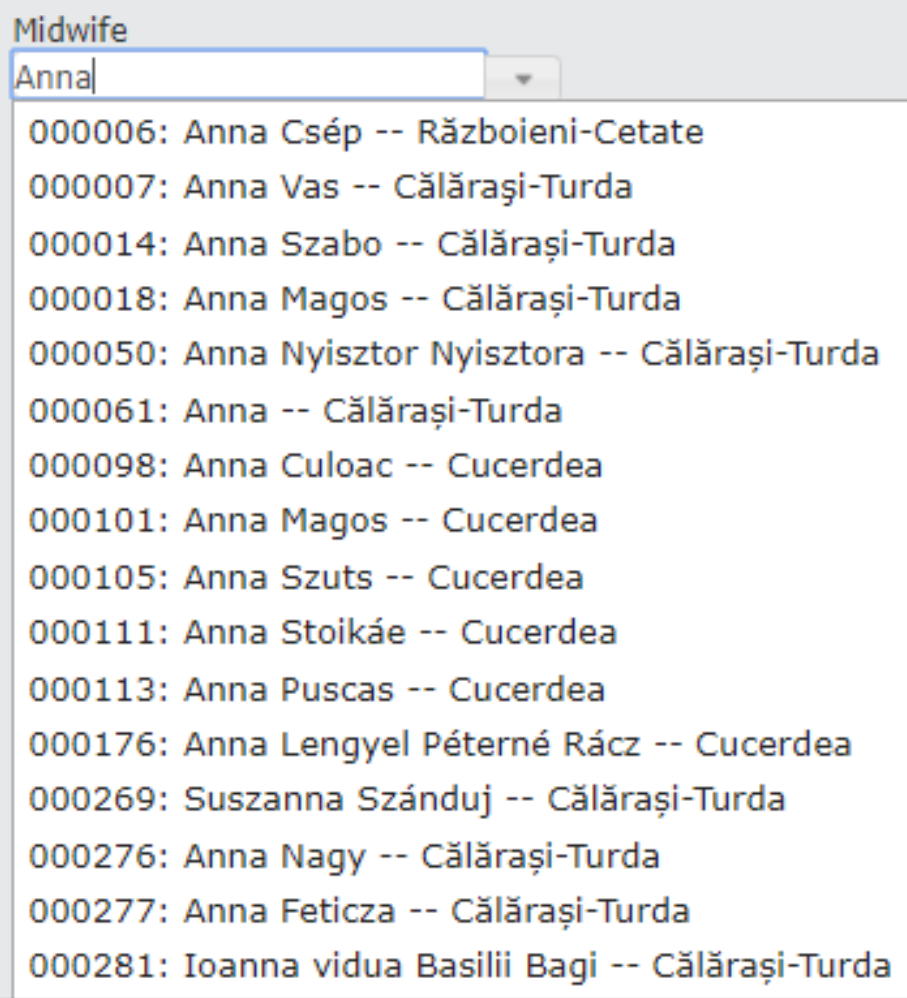

FIRST NAME, LAST NAME, NICKNAME. The same rules apply as to the similar fields from the previously detailed tables.

PLACE OF SERVICE. Same as the locality of the source.

RESIDENCE. To be filled in only if explicit information on the priest's residence is recorded in the source.

OCCUPATION. The same rules apply as to the similar fields from from the previously detailed tables.

JULIAN CALENDAR. The same rules apply as to the similar fields from from the previously detailed tables.

FIRST MENTION IN SOURCE. To be filled in following the format day/month/year (dd/mm/yyyy), and only with information mentioned by the source, marking the first mention of the midwife for all the events counted in the respective source.

LAST MENTION IN SOURCE. The same rules apply as to the field FIRST MENTION IN SOURCE, now marking the last mention of the midwife in the respective document(s). 
COMMENTS. The same rules apply as to the similar fields from from the previously detailed tables.

Some midwives were active for short periods of time or were present for a single event, others were professional midwives who birthed for decades in the same community. Similar to the table 'Priests', all the events associated with a midwife are listed for research and verification purposes (Figure $\mathbf{4 5}$ - the field COMMENTS includes all the name variants of the same midwife recorded in the source).

Figure 45. Listing of the events associated to a midwife code in HPDT

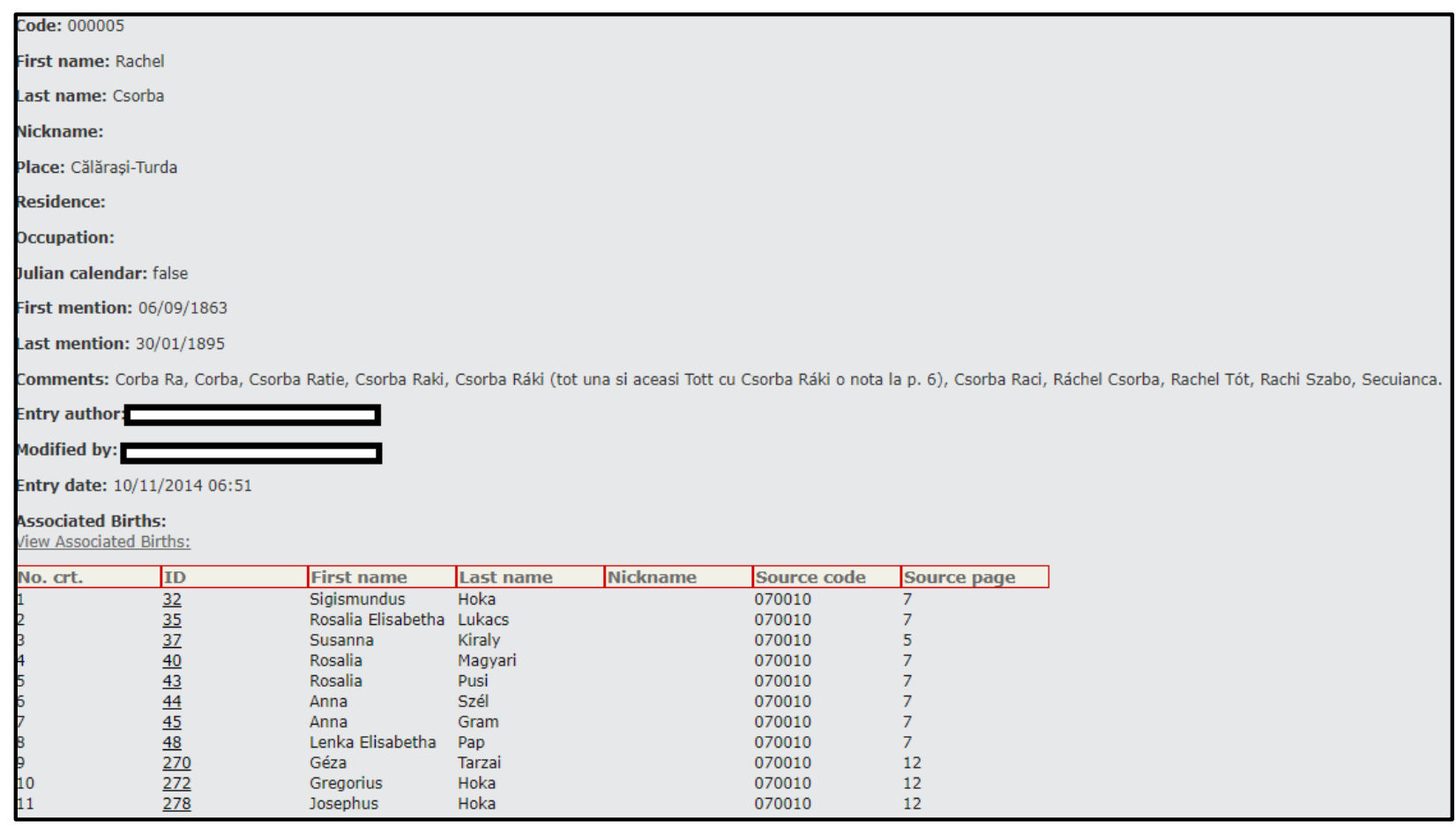


12. Table 'SOURCE'

Figure 46. Entry form for table 'Source'

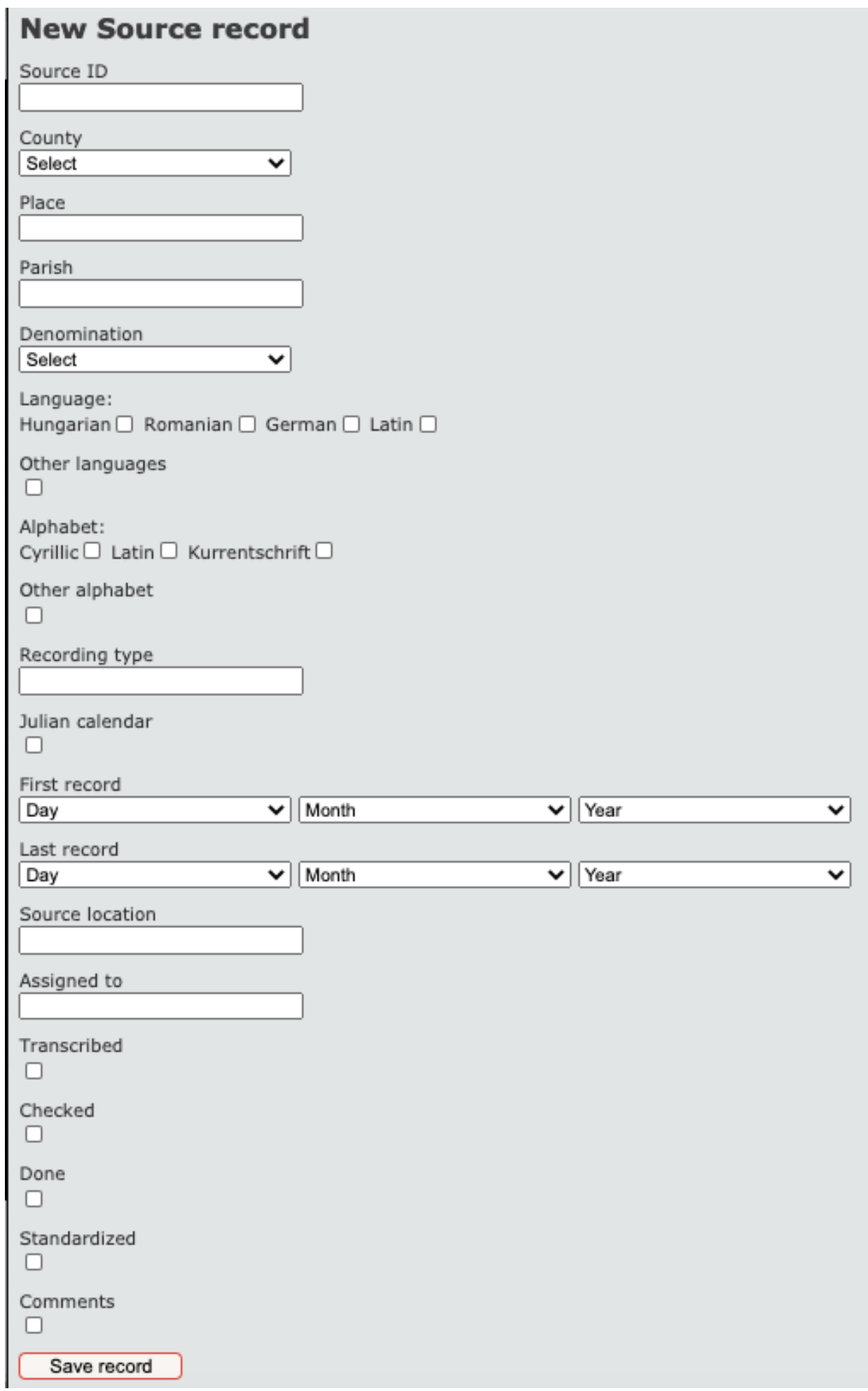

Source records are based on the description sheet filled in prior to beginning the data entry process (see Annex no. 1). Each source record is linked to all other 
records in the database extracted from the respective original source, thus allowing at any time the virtual recreation of the whole document (Figure 47).

Figure 47. Listing of the records associated with a source in HPDT

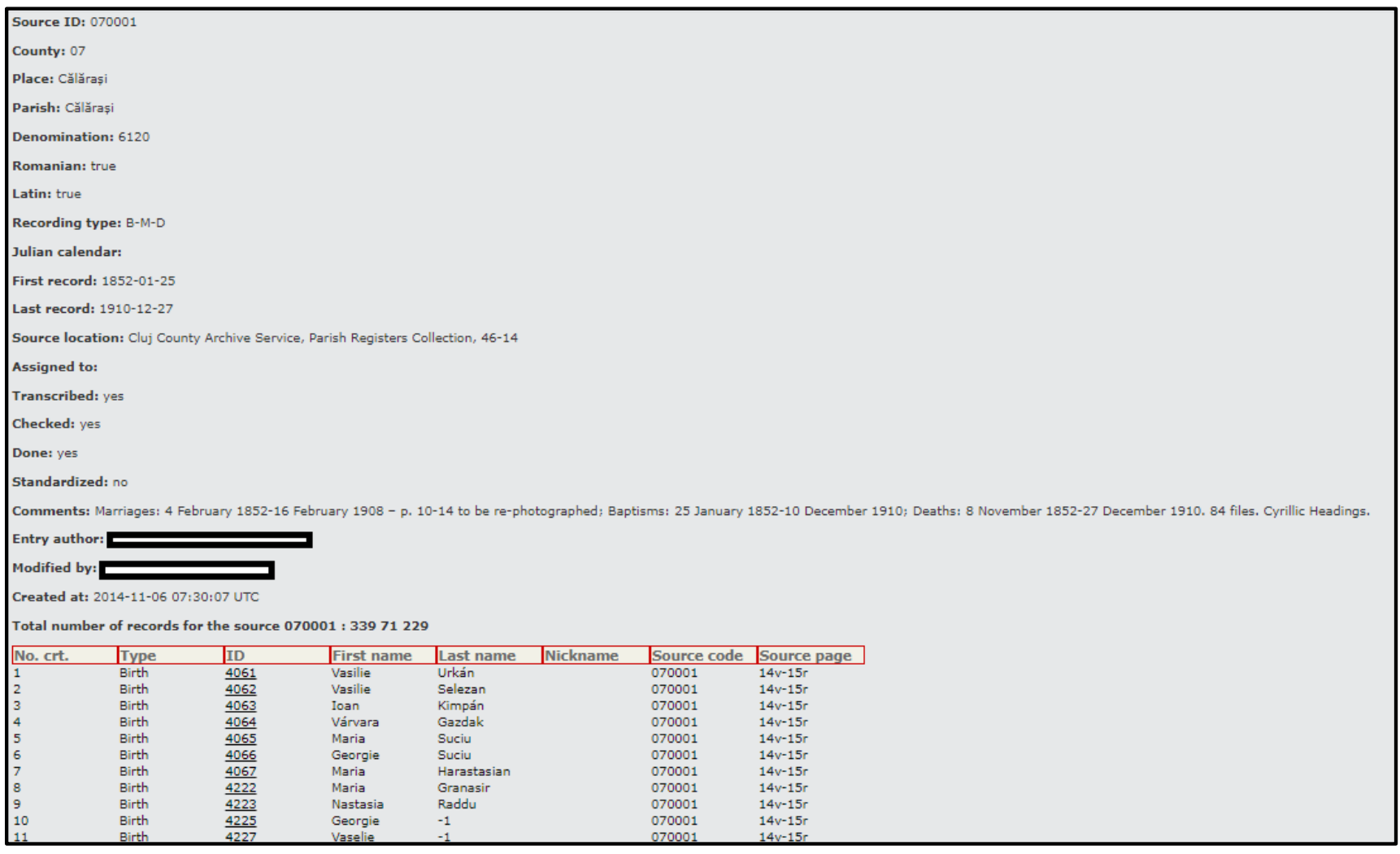

SOURCE ID. A unique six-digit code will be assigned to each source (e.g. 010001). The first two digits represent the code of the county in which the parish covered by the source is currently located. The last four digits distinguish between different sources within the same county.

COUNTY. The county of Romania in which the parish referred to in the source is currently located will be selected form the drop down menu. Each county has been assigned a unique two-digits code.

PLACE. Present-day name of the locality in which the parish referred to in the source was functioning.

PARISH. Name of the parish, as it appears in the source. It may be the older name of the locality, or a toponym, if more than one parishes of the same denomination were functioning in the same locality.

DENOMINATION. The denomination of the parish register. 
LANGUAGE (HUNGARIAN / ROMANIAN / GERMAN / LATIN). One or more of the checkboxes must be ticked, according to the language(s) used in the original source.

OTHER LANGUAGES. When ticked, opens a text field where other languages used in the original source can be added.

ALPHABET (CYRILIC / LATIN / KURRENTSCHRIFT). One or more of the checkboxes must be ticked, according to the alphabet(s) used in the original source.

OTHER ALPHABET. When ticked, opens a text field where other alphabets used in the original source can be added.

RECORDING TYPE. To be filled in with abbreviations according to the type of events recorded in the original source, as following: B (Births), Be (Betrothals), $\mathbf{M}$ (Marriages), D (Deaths), Cnf (Confirmations), Cnv (Converts). If the source records multiple types of events, the respective abbreviations should be used, separated by a hyphen (e.g. B-Be-M-D-Cnf-Cnv).

JULIAN CALENDAR. The same rules apply as to the similar fields from from the previously detailed tables.

FIRST MENTION IN SOURCE. To be filled in following the format day/month/year (dd/mm/yyyy), and only with information mentioned by the source, marking the date of the first recorded event, irrespective of its type.

LAST MENTION IN SOURCE. The same rules apply as to the field FIRST MENTION IN SOURCE, now marking the date of the last recorded event, irrespective of its type.

SOURCE LOCATION. The physical location where the source can be accessed must be filled in, including information about the County Archive Service, Collection and archive call number.

TRANSCRIBED / CHECKED / DONE / STANDARDIZED. Each of the checkboxes are to be ticked, following the processing stages of the source.

COMMENTS. The same rules apply as to the similar fields from from the previously detailed tables. For sources recording multiple types of events, the first and last occurance date of each type of event should be filled in. 


\section{The genealogical interface of the database}

The completion of the project conducted between 2014 and 2017 with the financial support of EEA Grants created an atmosphere of expectation among researchers, but also among passionates of genealogy and people who wished to find out more about their ancestors by means of digitized sources. The genealogical interface of the database was created with the aim of supporting such prospects (www.hpdt.ro:4080, accessed 03.04.2020). It addresses the general public and is based on HPDT sources' component, thus it provides information as extracted from the parish registers, strictly complying with the source and lacking any standardization features. The standardised database, currently under development, should gradually replace the sources' component as support for the genealogical interface, following the advancement of the cleaning and standardization procedures.

The genealogical interface covers three of the databases' main tables, namely 'Births', 'Marriages', and 'Deaths', which have previously been subjected to a primary record-linkage process. The search engine presents the users with multiple possibilities of identification of the individuals / ancestors, according to their interest and previous knowledge on the topic.

There are four main search fields: FIRST NAME, LAST NAME, PRESENT DAY LOCATION, and YEAR, which allow both field-focused and combined queries. Optionally, the chronological period can be refined by using the alternate search fields START YEAR and END YEAR.

The search engine returns all results corresponding to the querried string (e.g. the string 'ion' will return both first names 'Ion' and 'Dionisie'), but it does not support the use of Boolean operators within the search fields (e.g. a search for 'Ion' AND 'Ioan' will return no results). In the example from Figure 48, the search for the Firstname 'Eulampie' returned the Results displayed below: all the instances where 'Eulampie' was mentioned, meaning twice as a father of a baptized child and once as the father of a deceased one. We have selected a rare name, so that all three major events could be displayed on the same picture, as seen in Figure 48. 
Figure 48. Search results in the genealogical database

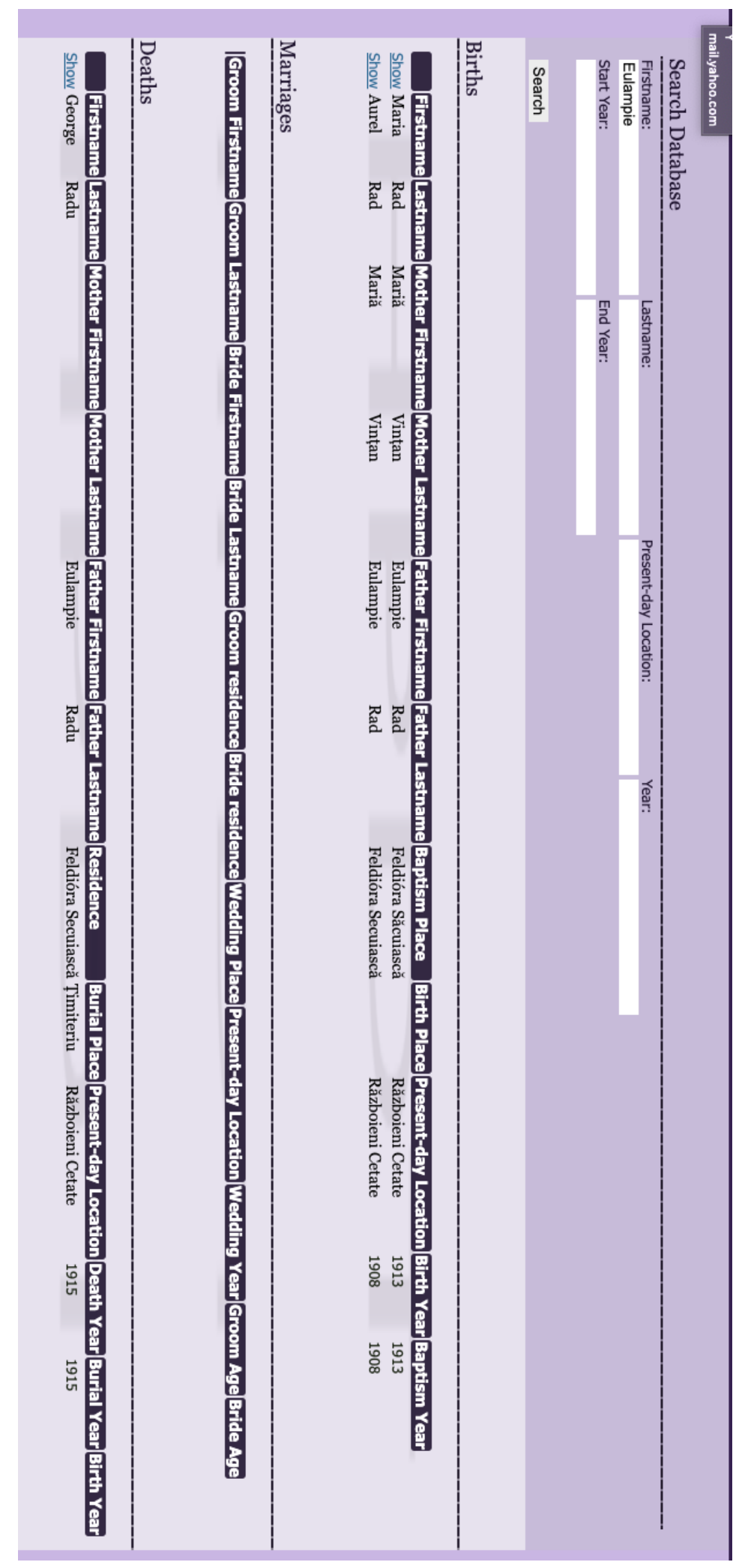

Basic queries of common names usually return dozens or hundreds of instances, so using other filters (e.g. Lastname, Location, Year) may help the users narrow their searches. 
Particular events are detailed by using the 'Show'/'Detalii' button, which opens an expanded form. In it, the mention 'missing/illegible' indicates that the information for the respective field is not present in the original source. If the information could not be deciphered due to exceptional palaeographic reasons (deteriorated registry, ink or other type of stains, overlapped writing, etc.), the situation is marked accordingly.

In the example below (Figure 49), we have dispayed the details regarding the first baptism from the results presented in Figure $\mathbf{4 8}$ above, where 'Eulampie' is registered as Father of the baptized.

Figure 49. Details of search results in the genealogical database

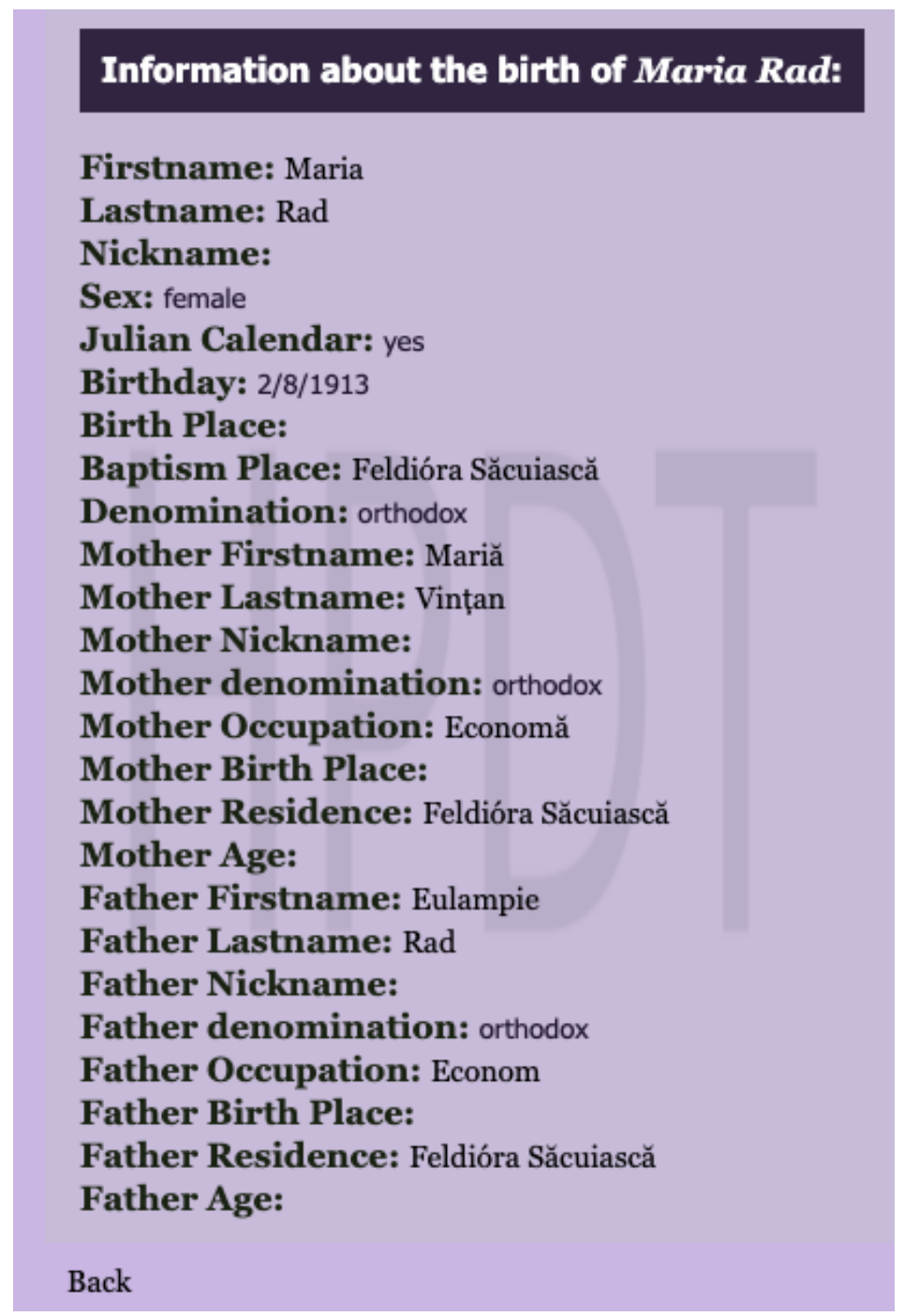

Given that the genealogical interface currently exploits only the sources' component of the database, public users may need to employ the auxiliary tools made available by the database owners in order to increase the relevance of the search results. Such tools are available on a dedicated page (http://82.208.133.141:4080/documents, accessed 02.04.2020) and include: a list of digitized sources, an onomastic catalogue, a public user manual, a catalogue of all 
parish registers preserved and accessible at the Romanian National Archives' county services in Transylvania, and a report on the final results of the original project which led to the construction of the database. The onomastic catalogue includes an extended list of names, together with all their spelling variations identified within HPDT, thus allowing the user to chose the best string of letters to search for, in order to cover a wide as possible range of results related to the desired name (e.g. in order to identify all bearers of the name 'loan' ('John'), it is currently recommended to use multiple string variations in order to widened the range of results, as this very common first name has no less than 25 different spelling variations only in Romanian, such as 'luon', 'Ioanu', 'luanu', 'loane', 'Ionuțiu', 'Onuțiu', 'Onuț', etc.) 


\section{Conclusions}

While manuals do not usually include an ending section, we thought that in this case some brief conclusive remarks would be required. As mentioned at the beginning of this paper, our original purpose was to deliver a working tool to the scientific community, respectively a database compatible with the current international standards (Mandemakers and Dillon 2004), as much as the sources and the logistics allowed it. The result was a database which replicates to a great extent the original source in terms of historical information, yet includes some normalization features, related mainly to the information recorded in a standardised manner in the parish registers (e.g. sex, legitimacy, denomination, ethnicity, key-role persons). Given that images of all the original sources are available in a dedicated digital repository, any queries raised by the replicated or normalized information can be resolved by confronting them with the database content.

One of the main challenges raised by such a complex tool is represented by its dependency on professional data-entry operators with advanced palaeographical training, necessary because of the particularities of the sources, and the above presented manual stands evidence in this regard. This, alongside the timeconsumming character of the data entry, verification, cleaning, standardization and linkage processes, makes HPDT a high-maintenance tool, providing sharp results only following thorough data processing and research, which in turn require adequate funding.

On the other hand, the project outcome generated lofty expectancies not only among researchers, but also among the genealogy enthusiasts, or simply people who wanted to find out more about their ancestors by means of digital tools. Due to the genealogical interface of the database, this information became available a mouse click away. According to Google Analytics, in January 2020, the genealogical interface of the database counted ca. 29.000 visitors, which is a rather high figure for Romania, a country in which there is only a faible tradition of popular genealogical research (Figure 50)

Figure 50. HPDT users on Google Analytics

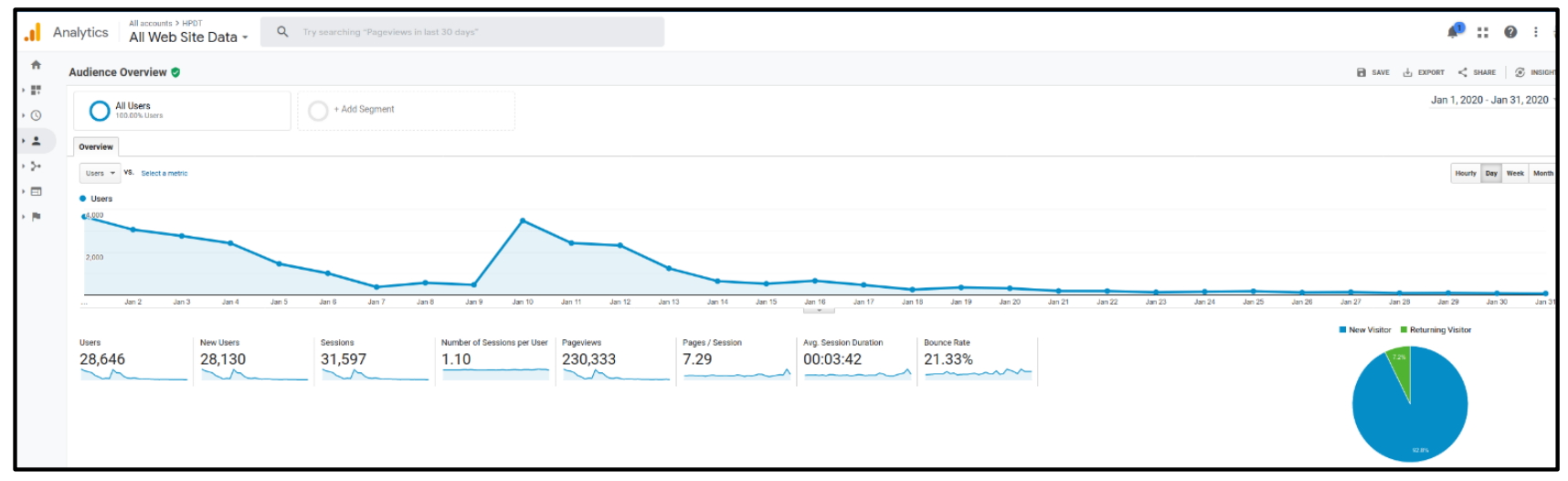


In regard to the research directions opened by HPDT, they cover, inter allia, areas such as history, demographics, sociology, economy, linguistics, and medical history from late $18^{\text {th }}$ to mid $20^{\text {th }}$ centuries. The addressed period of time represents a crucial era for the studying of fertility decline, urbanisation, household composition, occupational structure, and gender equality. The database allows advanced statistical analyses on aspects less studied until recently from a historical perspective, by making use of data from a micro-social level. In the sphere of social sciences, particularly the sociology of the family, HPDT enables new approaches on the organisation of the family, of the household, on social mobility, and various inter-generational processes. In the sphere of demographics, the phenomenon of the first demographic transition can be investigated through an approach to the micro-social level - which is highly different from the approaches already used for the Romanian/Transylvanian area. The models of fertility could be analysed according to different personal characteristics, such as class, religion, literacy, family structure. Moreover, aspects concerning the process of industrialisation as perceived at an individual level and the impact industrialisation had on the inter-generational relations can be studied - based on the data regarding occupational aspects or other economic related aspects. On top of the demographic, social, and economic characteristics of the individuals, the database will also allow new approaches in onomastics - ex. the evolution of names, the difference of name usage according to social-economic characteristics.

\section{Works cited}

Bolovan loan and Luminița Dumănescu. "Baza de date a populației Transilvaniei. Instrument pentru cercetarea de demografie istorică și istorie socială." Între pasiune și profesie. Istoriografia românească la început de mileniu, edited by I.A. Pop, I. Bolovan, O.M. Tămaș. Academia Română - Centrul de Studii Transilvane - Școala Ardeleană, 2017, pp. 269-295.

Bolovan loan and Luminița Dumănescu. "The Historical Population Database of Transylvania. A story of a work in progress." Mensch im Mittelpunckt. Bevölkerung, Ökonomie, Erinnerung. Festchrift für Peter Teibenbacher zum 65. Geburstag, edited by M. Hohenwarter, W.M. Iber, Th. Krautzer. Lit Verlag, 2019, pp. 133-146.

Botoș, Raluca. "Education as a Vehicle for Social Mobility in the 19th Century in Transylvania. A Comparative View on Romanians and Hungarians in the Gurghiu Valley." Romanian Journal of Population Studies, vol. 13, no. 1, 2019, pp. 29-46.

Coroian, Izabela Georgiana. "The Seasonality of Mortality in Three Transylvanian Settlements in the Second Half of the 19th Century." Romanian Journal of Population Studies vol. 10, no. 1, 2016, pp. 19-35;

Crăciun, Bogdan, Elena Crinela Holom and Vlad Popovici. "Historical Population Database of Transylvania: Methodology Employed in the Selection of Settlements and Micro Zones of Interest." Romanian Journal of Population Studies, vol. 9, no. 2, 2015, pp. 17-30. 
Farkas, Tamás "A Selected and Annotated Bibliography for the Research of Official Surname Changes in Hungary." Hungarian Cultural Studies. E-journal of the American Hungarian Educators Association, vol. 5, 2012, https://ahea.pitt.edu/ojs/index.php/ahea/article/view/87/74, at 20.05.2020.

Holom, Elena Crinela, Oana Sorescu-ludean and Mihaela Hărăguș. "Beyond the Visible Pattern: Historical Particularities, Development, and Age at First Marriage in Transylvania, 1850-1914." The History of the Family, vol. 23, no. 2, 2018, pp. 329-358.

van Leeuwen, Marco H.D., Ineke Mass and Andrew Miles. Historical International Standard Classification of Occupations. Leuven University Press, 2002.

Lumezeanu, Angela, "Insight into designing and building a historical population database." Romanian Journal of Population Studies, vol. 12, no. 2, 2018, pp. 77-98.

Lumezeanu, Angela. Digital Infrastructure for Social History. Ph.D. Thesis, BabeșBolyai University, 2019.

Mandemakers, Kees and Lisa Dillon, "Best Practices with Large Database on Historical Populations." Historical Methods: A Journal of Quantitative and Interdisciplinary History, vol. 37, no. 1, 2004, pp. 34-38.

Mârza, Daniela. "Patterns in Family Relationships in 19th Century Transylvania (Data from the Historical Population Database of Transylvania)." Transylvanian Review, vol. 26, no. 4, 2017, pp. 63-70.

Mârza, Daniela. "Rhythms of Dying in Transylvania, 1850-1914 (data on mortality from Historical Population Database of Transylvania)." Transylvanian Review, vol. 25, supplement no. 2, 2016, pp. 196-202.

Rotar, Marius. "Death inspectors or the 'professionals' of death during the late nineteenth and early twentieth century Transylvania." Mortality: Promoting the interdisciplinary study of death and dying, vol. 17, no. 3, 2012, pp. 240-255. 
Annex no. 1. Source description sheet ${ }^{*}$

\section{Source presentation}

\begin{tabular}{|c|c|c|c|c|c|c|c|c|c|c|c|c|}
\hline $\begin{array}{c}\text { Source } \\
\text { ID' }\end{array}$ & County & Place & Parish $^{2}$ & Denomination & Language & Alphabet & Recordings_type $^{3}$ & Calendar (J/G) & First record $^{4}$ & Last record ${ }^{5}$ & Source location, call no. & Observations $^{6}$ \\
\hline 010031 & Alba & $\begin{array}{l}\text { Ocna } \\
\text { Mureș }\end{array}$ & $\begin{array}{l}\text { Ocna } \\
\text { Mureș }\end{array}$ & $\begin{array}{c}\text { Calvinist } \\
\text { (Reformed) }\end{array}$ & Hungarian & Latin & B-M-D-Cnv-Cnf & G & 1876.01 .09 & 1890.12 .30 & $\begin{array}{c}\text { Alba County Archive } \\
\text { Service, Parish Registers } \\
\text { Collection, } 1859\end{array}$ & 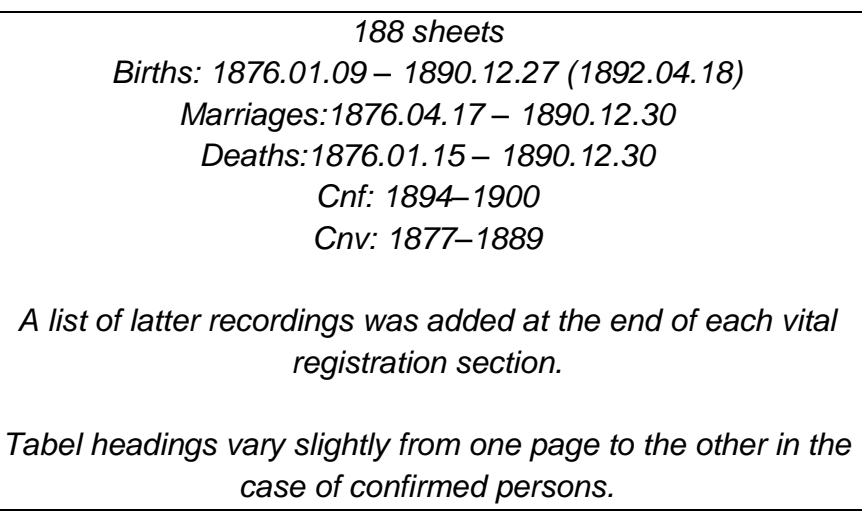 \\
\hline
\end{tabular}

Table headings

Baptisms: event no., year and date of birth and baptism, name of the baptized (boy or girl), legitimacy, name, confession and social standing of the parents, address and house no., name and social standing of the godparents, name of the baptizing priest, name of the midwife, remarks.

Weddings: event no., year and date of the event, name, social standing, birthplace and residence with house no., confession, age, marital status (unwedded, widow) of the groom and bride, name and social standing of the betrothal and wedding witnesses, name of the priest, if the regular marriage banns took place, or if a dispensation latter has been issued, remarks.

Deaths: event no., year and date of death, name and social standing of the deceased, name and social standing of the husband if the deceased is a woman, name and social standing of the father if the deceased is a child, birthplace and residence with house no., age, cause of death, place and date of burial, name of the burial priest, remarks.

Confirmations: event no., name of the newly confirmed, birthplace and residence, year of birth, remarks (including data on the comfirmed's degree of literacy).

Conversions to Calvinism: event no., year and date of the conversion, previous confession, place of birth and residence of the newly converted, name of the priest, witnesses for renouncing the old faith, witnesses for accepting the new faith, remarks.

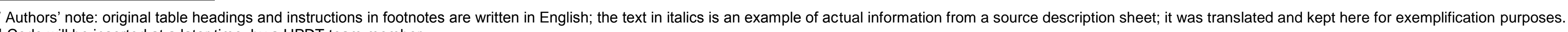
1 Code will be inserted at a later time, by a HPDT team member.

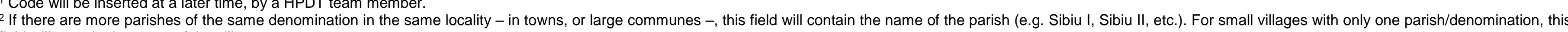
field will contain the name of the village.

${ }^{3}$ Legend: B (baptisms), M (marriages), D (deaths), Cnf (confirmations), Cnv (conversions), Bless (blessings), V (vaccinations). Example: B-M-D-Bless-Cnf

4 YYYY.MM.DD. Correct: 1850.12 20 Incorrect: 20.12.1850 Correct: 1850.12.02, 1850.07.02. Incorrect: 1850.12.2, 1850.7.2.

YYYY.MM.DD.

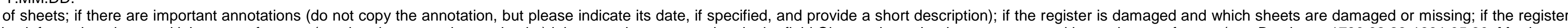

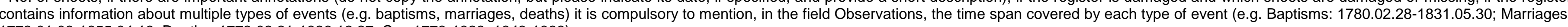
1773.01.08-1855.04.18; Deaths: 1773.02.21-1826.12.27; Cnv 1773-1828, 1843-1883). 
Table 'PRIESTS'

\begin{tabular}{|c|c|c|c|c|c|c|c|c|c|c|c|}
\hline Code $^{7}$ & First name & Last name & Nickname & Place of service & Parish & Denomination & Residence & Calendar (J/G) & First mention ${ }^{8}$ & Last mention ${ }^{9}$ & Observations \\
\hline 000603 & István Gy. & Szigeti & & Ocna Mureș & & Calvinist & Ocna Mureș & $G$ & 1876.01 .15 & 1876.04 .23 & \\
\hline 000685 & György & Földes & & Ocna Mureș & & Calvinist & Ocna Mureș & $G$ & 1876.05 .04 & 1881.04 .20 & \\
\hline 000708 & János & Sándor & & Ocna Mureș & & Calvinist & Mirăslău & $G$ & 1879.05 .25 & 1879.05 .25 & Miriszló [priest from] \\
\hline 000612 & Dávid & Pap & & Ocna Mureș & & Calvinist & Noșlac & $G$ & 1879.06 .20 & 1881.09 .20 & N. Lak [priest from] \\
\hline 000605 & Beniámin\&Benjámin & Pap\&Pop & Az oláh pap & Ocna Mureș & & Orthodox?? & & $G$ & 1881.05 .28 & 1887.10 .02 & \\
\hline$[\ldots]$ & & & & & & & & & & & \\
\hline $\begin{array}{l}\text { Lay } \\
\text { persons }\end{array}$ & & & & & & & & & & & \\
\hline$L 00033$ & Antal & Pethö & & Ocna Mureș & & Calvinist & Ocna Mureș & $G$ & 1876.01 .27 & 1890.04 .11 & Cantor [church singer] \\
\hline
\end{tabular}

Table 'MIDWIVES'

\begin{tabular}{|c|c|c|c|c|c|c|c|c|c|}
\hline $\operatorname{Code}^{10}$ & First name & Last name & Nickname & Place of service & Place of residence & Calendar (J/G) & First mention $^{11}$ & Last mention $^{12}$ & Observations \\
\hline 001473 & & & Jánosiné & Ocna Mureș & & $G$ & 1876.01 .09 & 1876.02 .19 & \\
\hline 001461 & Sarolta & Kovács & Gulácsi Albertné\&Gulácsiné & Ocna Mureș & & $G$ & 1876.01 .04 & 1890.12 .12 & \\
\hline 001475 & Anna\&Ána & Nikóra\&Nyikor & & Ocna Mureș & & $G$ & 1876.04 .15 & 1878.09 .23 & \\
\hline
\end{tabular}

Mandatory steps for quickly establishing the first and the last mention of priests and midwives:

Step 1: start by going through the whole register, from the first to the last recorded event, and extract the names of the priests and their first date of occurrence/mention ONLY;

Step 2: go through the register in reverse, from end to beginning, and extract the last date of occurrence/mention of the priests;

Step 3: if you are working with a 'Baptisms' register, repeat the previous two steps for the midwives. Never extract priests and midwives at the same time;

Corollary: if the number of midwives surpasses 40-50 (usually in big cities or in highly scattered mountain villages) you should use a different approach: instead of going forth and back through the register, just go from the beginning to the end and keep modifying the last date of occurrence/mention each time the midwife is re-mentioned.

\begin{tabular}{|c|c|}
\hline Filled in by .................. (volunteer) & Date (YYYY.MM.DD) \\
\hline Filled in/verified by .................. (data-entry operator) & Date (2015.10.29) \\
\hline Verified and codes inserted by .................... (HPDT team member) & Date (2015.11.01) \\
\hline Data input into HPDT by ..................... (data-entry operator) & End date (2016.03.14) \\
\hline
\end{tabular}

\footnotetext{
Code will be inserted at a later time, by a HPDT team member.

YYYY.MM. DD. Correct: 1850.12.20 Incorrect: 20.12.1850. Correct: 1850.12.02, 1850.07.02. Incorrect: 1850.12.2, 1850.7.

9 YYYY.MM.DD.

inserted at a later time, by a HPDT team member.

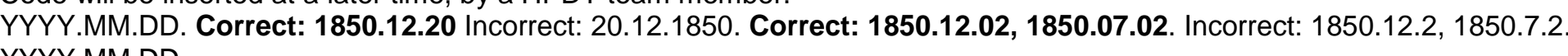

Studia UBB Digitalia, Volume 64 (LXIV) 2019, June, Issue 1 